\title{
In-utero and perinatal influences on suicide risk: a systematic review and meta-analysis
}

Massimiliano Orri, ${ }^{1,2}$ David Gunnell, ${ }^{3,4}$ Stephane Richard-Devantoy, ${ }^{1}$ Despina Bolanis, ${ }^{1}$ Jill Boruff, ${ }^{5}$ Gustavo Turecki ${ }^{1}$ \& Marie-Claude Geoffroy ${ }^{1,6}$

\author{
Affiliations \\ ${ }^{1}$ McGill Group for Suicide Studies, Douglas Mental Health University Institute \& Department of Psychiatry, McGill \\ University, Montreal, Canada \\ ${ }^{2}$ Bordeaux Population Health Research Centre, Inserm U1219, University of Bordeaux, Bordeaux, France. \\ ${ }^{3}$ Population Health Sciences, University of Bristol, Bristol, UK. \\ ${ }^{4}$ National Institute of Health Research Biomedical Research Centre at the University Hospitals Bristol NHS \\ Foundation Trust and the University of Bristol, Bristol, UK \\ ${ }^{5}$ Schulich Library of Physical Sciences, Life Sciences, and Engineering, McGill University, Montréal, Canada. \\ ${ }^{6}$ Department of Educational and Counselling Psychology, McGill University, Montreal, Canada
}

\section{Corresponding author}

Prof Marie-Claude Geoffroy, McGill Group for Suicide Studies, Douglas Mental Health University Institute, Frank B. Common Pavilion, 6875 LaSalle Boulevard, Montreal H4H 1R3, Canada (marie-claude.geoffroy@mcgill.ca). 


\section{Summary}

Background. Adverse in-utero and perinatal conditions may contribute to a heightened suicide risk throughout the lifespan, however existing evidence is sparse and contradictory. We did a systematic review and meta-analysis to investigate in-utero and perinatal exposures associated with suicide, suicide attempt, and suicidal ideation.

Methods. We searched MEDLINE, Embase, and PsycINFO from inception to January 24, 2019 for population-based prospective studies investigating the association between in-utero and perinatal factors and suicide, suicide attempt, and suicidal ideation. We calculated pooled odds ratio (ORs) with 95\% CIs using random-effects models and used meta-regression to investigate heterogeneity.

Findings. We identified 42 studies; they had a low risk of bias (median quality score 9/9; range 5-9). Family/parental characteristics, such as high birth order (eg, pooled ORs fourth or later born vs first born 1.52, 1.21-1.88), teenage mothers $(1.80,1.52-2.14)$, single mothers $(1.57,1.31-1.89)$, indices of socioeconomic position such as low maternal $(1.36,1.28-1.46)$ and paternal $(1.38,1.27-1.51)$ education, and foetal growth - low birthweight $(1.30,1.09-1.55)$ and small-for-gestational-age (1.18. 1.00-1.40) were associated with higher suicide risk. Father's age, low gestational age, obstetric characteristics (eg, caesarean section), and condition/exposure during pregnancy (eg, maternal smoking or hypertensive disease) were not associated with higher suicide risk. Similar patterns of associations were observed for suicide attempt and suicidal ideation; however, these results were based on a lower number of studies. In metaregression, differences in length of follow-up explained most between-study heterogeneity.

Interpretation. These findings suggest that prenatal and perinatal characteristics are associated with increased suicide risk during the life course, supporting the developmental origin of health and diseases hypothesis for suicide. The low number of studies for some risk factors, especially for suicide attempt and ideation, leaves gaps in knowledge that need to be addressed. The mechanisms underlying the reported associations, and their causal nature still remain unclear.

Funding. European Union's Horizon 2020. 


\section{Introduction}

Suicide is an important cause of mortality worldwide, with an estimated global burden of 800000 deaths each year, ${ }^{1}$ and its prevention is of paramount importance. The need for prevention extends to non-fatal suicide attempt and severe suicidal ideation, as both carry serious long-term consequences ${ }^{2}$ including increased risk of suicide death. ${ }^{3}$

Suicide is a complex and multifactorial phenomenon with both proximal (eg, mental disorders, economic breakdowns) and distal (eg, childhood adversities) risk factors. ${ }^{4}$ In keeping with the developmental origins of health and disease $(\mathrm{DOHaD})$ model, $^{4-8}$ an increasing number of studies have reported associations of in-utero and perinatal factors with suicide and mental disorders. ${ }^{9,10}$ While the contribution of in-utero and perinatal conditions is well established for a range of non-communicable diseases such as cardiovascular and metabolic comorbidities, ${ }^{11-13}$ evidence is less consistent for psychiatric disorders and suicide. ${ }^{14,15}$ For example, prior studies have reported an increased risk of suicide for individuals born with a low birthweight ${ }^{16}$ or individuals exposed to maternal smoking during pregnancy, ${ }^{17}$ whereas others have failed to replicate these associations. ${ }^{18,19}$ Such inconsistencies may be accounted for by heterogeneity of studies in terms of country of origin, study design and length of follow-up. Further, as both suicide and most in-utero/perinatal factors (such as low birthweight) are rare at the population-level, failure to find an association in some studies may be attributable to the lack of statistical power despite large sample sizes. We are unaware of any systematic review of the in-utero and perinatal influences on suicide using statistical approaches increasing the statistical power (such as meta-analysis).

We conducted a systematic review and meta-analysis of the available evidence on the association between inutero and perinatal risk factors (including in-utero conditions, maternal-related factors, and socioeconomic conditions at birth) and suicide, suicide attempt, and suicidal ideation. Findings from such a study may provide insight supporting the DOHaD hypothesis for suicide risk, thus informing public health preventive interventions focusing on early maternal and child care.

\section{Methods}

\section{Search strategy and selection criteria}

This systematic review was conducted in accordance with Meta-analyses Of Observational Studies in Epidemiology (MOOSE) guidelines. ${ }^{20}$ The protocol was registered in PROSPERO (number CRD42018091205). A health science librarian (JB) searched the following databases from their inception until January 24, 2019 for published studies on inutero and perinatal factors and suicide: MEDLINE, Embase, and PsycINFO. The search was restricted to studies 
published in English. Additionally, we searched the reference lists of all identified publications and hand searched key journals. Only published studies were considered. A search strategy was developed for MEDLINE and modified for the other databases. Using a combination of free text and controlled vocabulary terms (see appendix), we searched terms from three categories: in-utero and perinatal factors (eg, "birthweight", "parent* age", "foetal growth"), suiciderelated outcomes (eg, "suicide*", "suicide attempt", "suicidal ideation", "self-harm"), and studies with a prospective design (eg, "longitudinal", "registries", "epidemiological studies"), combined using the Boolean operator "and".

Two investigators (MO and DB) independently screened the identified records for eligibility, first by title or abstract, followed by assessing the full-text (agreement on inclusion, weighted $\mathrm{k}=0.98$ ); discrepancies were resolved by discussion with a third investigator (MCG). Studies were included if they: (1) were population-based longitudinal studies or case-control studies nested in a cohort (ie, linkage of population registries or population-based cohort studies), and (2) reported on associations between any in-utero (any gestational period) and perinatal (measure up to one year of age) exposures or conditions and suicide, suicide attempt or suicidal ideation. Studies assessing self-harm defined as non-suicidal self-injuries were excluded.

\section{Data extraction and quality assessment}

Two investigators (MO and DB) independently extracted the following information from the selected articles: name of the first author, year of publication, name of the cohort (or information about the register), study location (country), number of participants, birth year of the participants, year at which the outcomes were assessed, participants' age at outcome assessment, risk factors investigated, outcome(s) investigated, number of cases and non-cases among exposed and non-exposed to each risk factor. If information was unavailable or unclear from a published report, corresponding authors were contacted to obtain the relevant data.

Study quality was assessed using the Newcastle-Ottawa Quality Assessment Scale for cohort studies. ${ }^{21}$ The scale assesses the quality of three domains of a study: participant selection (eg, representativeness of the exposed cohort), comparability of exposed and non-exposed groups (eg, whether the analysis accounted for confounding factors), and ascertainment of outcome (eg, adequacy of follow-up). For each characteristic within these three domains, a point was given if the criterion was fulfilled, except for comparability criterion that could score 0,1 or 2 points (score range, 0-9). Two investigators (MO and $\mathrm{DB}$ ) independently assessed the quality of the articles. Agreement between the investigators was high (weighted $\mathrm{k}=0.86$ ), and remaining discrepancies were resolved by discussion with a third investigator (MCG).

\section{Data analysis}


We did separate meta-analyses to estimate the association between each identified risk factor and suicide, suicide attempt, and suicidal ideation when raw data were provided for at least 2 studies. When it was not possible to pool the estimates, or information to perform meta-analysis was lacking (ie, single studies), we summarized evidence narratively. Our procedure to harmonize exposure categorization across studies is described in appendix. For exposures investigated in more than one study from the same cohort/linkage, we selected the study with the longest follow-up. We calculated crude odds ratios (OR) and 95\% confidence intervals (CIs) to compare lifetime suicide risk of individuals exposed to a given risk factor versus those non-exposed. Pooled ORs with $95 \%$ CIs were calculated using random-effect models. ${ }^{22}$ Given the range of different measures used to compute adjusted associations (eg, hazard ratios, odds ratios), adjustment variables investigated (eg, socioeconomic position, mental health), and exposure categorisation (eg, mother's age $<20$ versus $\geq 20$ in one study, and $<20$ versus $20-25$ versus $\geq 25$ in another), we were not able to pool consistent adjusted estimates. However, we narratively reported whether adjusting for confounding variables yielded changes in the crude estimates in the single studies and performed sensitivity analyses. Forest plots were generated showing ORs with corresponding 95\% CIs for each study and the overall random-effect pooled estimate. We assessed heterogeneity across studies using the Cochrane Q statistic and the $\mathrm{I}^{2}$ statistic (higher values representing higher heterogeneity), ${ }^{23}$ and used meta-regression and subgroup analyses to explore potential sources of heterogeneity (ie, age at follow-up, study design, and differences in the categorization of the exposure variables) and the influence of individual studies. Risk of publication bias was assessed with visual inspection of the funnel plots, and further inspected using the Egger test ${ }^{24}$ and the Duval and Tweedie trim-and-fill method. ${ }^{25}$

\section{Role of funding sources}

This project has received funding from the European Union's Horizon 2020 research and innovation programme under grant agreement No. 793396 and the Canadian Institutes of Health Research. The funders of the study had no role in study design, data collection, data analysis, data interpretation, or writing of the report. The corresponding author had full access to all the data in the study and had final responsibility for the decision to submit for publication.

\section{Results}

From the initially retrieved 3013 unique records, 42 articles met our inclusion criteria (Figure 1) and were retained for this study. The articles consisted of data that were drawn from 21 different cohorts $(\mathrm{n}=10$ cohort studies and $\mathrm{n}=11$ population registers) from Europe $(n=15)$, North America $(n=3)$, Taiwan $(n=1)$, and New Zealand $(n=1)$, and Brazil $(n=1)$. Sample sizes ranged from 140 to 3300708 , and follow-up from 2 to 70 years. Suicide mortality was an 
outcome in 14 of 21 cohorts, suicide attempt in 9 of 21, and suicidal ideation in 4 of 21 (Table 1). Methodological quality of the retained studies was high for observational studies (overall satisfactory quality of evidence; Table 2): most studies showed limited evidence of selection bias, had long follow-up and were based on secure records for the assessment of exposures and outcomes (eg, linkage of hospital or death registers).

Figure 2 shows the perinatal factors investigated in the included studies. Studies investigating the association between family and parental characteristics and suicide risk suggested that suicide risk was heightened for second or later born individuals compared to first born individuals. The pooled OR for this comparison was 1.22 (95\%CI 1.121.34; $\mathrm{n}=10$ studies; Figure 3). Restricting the analysis to 7 of the 10 studies allowed us to test dose-response associations between birth order and suicide: the pooled OR for the comparison between second-to-third born versus first born was 1.18 (1.07-1.30) and for the comparison between fourth or later born and first born was 1.51 (1.211.88), suggesting an increased suicide risk for increasing birth order. Most studies adjusting for confounding factors in multivariate analyses (such as maternal age, socioeconomic status, and sex), reported dose-response associations between increasing birth order and suicide, with adjusted associations being 10-20\% stronger than crude associations. There was also evidence of an association in two within-family studies comparing siblings from the same family (thus accounting for family-related confounding factors). ${ }^{26,27}$ One study showed that suicide risk was similar when the analyses were stratified according to the time since the birth of the previous child (eg, adjusted hazard ratio [HR] were 1.41 when the previous child was born 2 years earlier, 1.24 when the child was born 2-3 years earlier, and 1.49 when the child was born $>3$ years earlier) ${ }^{26}$ while another study showed that suicide risk persisted when the analyses were stratified by sibship size. ${ }^{28}$ The association, however, was less clear for suicide attempt. The risk of suicide attempt was not heightened for second or later born children compared to first born children, with a pooled OR of $1.17(0.97-$ 1.41, n=5 studies; Figure 4). One study only found statistical evidence for an association between birth order and suicidal ideation for the comparison between fourth or later born children versus first born children (adjusted OR 1.48, 1.06-2.07). ${ }^{29}$ For mother's age at child birth, suicide risk was heightened for offspring of younger mothers $(<20$ years of age) compared to those born to older mothers ( $\geq 20$ years of age), with a pooled OR of $1.80(1.52-2.14, n=7$ studies). Adjustment for various confounding factors in single studies (eg, birth order, socioeconomic status) did not account for this association. Associations were also found for suicide attempt and younger mothers (pooled OR 1.81, 1.32-2.50, $\mathrm{n}=4$ studies) but not for suicidal ideation (pooled OR 1.28, 0.84-1.94, $\mathrm{n}=2$ studies). No evidence of increasing suicide risk was found for individuals born to young ( $<25$ years) or older fathers ( $>35$ years) compared to those born to fathers aged 25-35, with pooled ORs of $1.24(0.90-1.71, \mathrm{n}=4$ studies $)$ and $1.05(0.88-1.25, \mathrm{n}=4$ studies), 
respectively. However, subgroup analyses stratified by age at outcome assessment indicated that indicated that in studies with $>30$ years follow-up there was evidence of increased risk amongst those with older fathers. Additionally, one study using a robust within-sibling design reported heightened risk of suicide attempt for offspring born to fathers aged 45 years or older compared to fathers aged 20-24 years (HR 2.72, 2.08-3.56). ${ }^{30}$ For household composition at child birth, the pooled OR for the comparison between single-mother households (ie, single, widowed, divorced mothers at child birth) versus non-single mother households was 1.57 (1.31-1.89, $\mathrm{n}=7$ studies). Most studies adjusted for relevant confounding factors, such as socio-economic status, child sex, and other family variables (eg, maternal age), and no major variations in the estimates was detected. These results were consistent for suicide attempt (pooled OR 1.78, 1.29-2.45, $\mathrm{n}=3$ studies), but no association was reported for suicidal ideation in one study (OR 1.21, 0.861.37). ${ }^{31}$

For variables describing family socioeconomic position at birth, the pooled OR for higher versus lower parental education (ie, up to primary/lower secondary school) was similar for mothers $(1.36,1.28-1.46, \mathrm{n}=3$ studies $)$ and fathers $(1.38,1.27-1.51, \mathrm{n}=2$ studies). Adjustment for confounding factors (eg, parental age, birthweight and birth order) did not explain associations in any of the studies. Suicide attempt (OR 1.33, 0.96-1.83) ${ }^{32}$ and suicidal ideation $(\text { OR } 0.94,0.82-1.14)^{31}$ were not associated with maternal education in the two studies that investigated this, although for suicide attempt the strength of the association (OR 1.33) was consistent with that seen for suicide. Individuals from low socioeconomic status at birth (parents' unskilled/manual work) were at increased risk of suicide (pooled OR 1.27, 1.00-1.61, $\mathrm{n}=6$ studies) or suicide attempt (pooled OR 1.75, 1.45-2.09, $\mathrm{n}=5$ studies) but not suicidal ideation (OR 1.23, $0.76-1.57),{ }^{31}$ compared to individuals with higher socioeconomic status.

Several studies investigated the association between various indices of foetal growth and suicide risk. Evidence of increased risk was found across five studies comparing suicide risk for individuals with low $(<2500 \mathrm{~g})$ versus normal birthweight ( $\geq 2500 \mathrm{~g}$ ), with a pooled OR of 1.30 (1.09-1.55). Such risk was not explained by other inutero and maternal confounding variables (eg, gestational age, obstetric characteristics, mother's age and parity). Consistently, there was an increased risk of suicide attempt (pooled OR 1.39, 1.23-1.56, $\mathrm{n}=2$ studies) and suicidal ideation (pooled OR 1.73, 1.04-2.86, $\mathrm{n}=2$ studies) for individuals born with low birthweight. Low gestational age at birth (ie, prematurity) was not associated with suicide, with a pooled OR of $1.11(0.98-1.25$; $n=5$ studies) for low ( $<36 / 38$ weeks) versus non-low gestational age $(\geq 36 / 38$ weeks). However, an association was found for being small for gestational age at birth, with a pooled OR of $1.18(1.00-1.40, \mathrm{n}=4$ studies $)$. Concerning suicide attempt, an association was reported for low gestational age in two studies (pooled OR 1.09, 1.04-1.15), although this comparison 
was mainly influence by one study (99.8\% weights). One study reported a higher risk in the lowest category of birth length $(<47 \mathrm{~cm})$ relative to the reference category $(50-51 \mathrm{~cm})$, with a crude HR of $1.36(1.01-1.84)$ for suicide and an adjusted HR of 1.29 (1.18-1.41) for suicide attempt. ${ }^{16}$ One study reported no association between small head circumference at birth $(<32 \mathrm{~cm}$ versus $\geq 32 \mathrm{~cm})$ and suicide,,${ }^{17}$ but another study reported an association with suicide attempt (adjusted OR 2.2, 1.1-4.6). ${ }^{33}$

Several studies investigated associations between obstetric characteristics and suicide but found no statistical evidence of an association with caesarean section versus vaginal delivery (pooled OR 1.13, 0.92-1.40, $\mathrm{n}=2$ studies) and placenta abruption (adjusted HR 1.60, 0.51-4.98). ${ }^{17}$ Similarly, a study found no statistical evidence of an association between 5-min Apgar score $<7$ and suicidal ideation (adjusted OR 1.9, 0.73-5.0), ${ }^{33}$ whereas another study reported an association between caesarean section and suicide attempt (OR 1.09, 1.00-1.18). ${ }^{16}$

Finally, maternal physical and psychological prenatal conditions and exposures during pregnancy were investigated for their association with suicide risk. Four studies investigated associations between maternal smoking during pregnancy and suicide mortality. The pooled OR for the comparison between mothers smoking $\geq 1$ cigarettes/day versus mothers smoking $<1$ cigarettes/day was 1.56 (0.99-2.46, $\mathrm{n}=4$ studies). Studies investigating the number of cigarettes/day did not report a clear dose response association. ${ }^{17,34}$ It is worth noting that these studies revealed potential confounding effects of perinatal and family variables: in one study, the effect of maternal smoking was only seen for the comparison between mother smoking $>10 \mathrm{vs}<1$ cigarettes/day after adjustment for child's sex, gestational age, birthweight, 5-minute Apgar score, maternal age, parity, and mother's psychiatric diagnosis before the child's birth. ${ }^{34}$ In another study, the effect of maternal smoking was attenuated when the analysis was restricted to sibling pairs discordant for suicidal acts and prenatal smoking exposure. ${ }^{17}$ Weak evidence for an association with suicide was reported for mother chronic illness ${ }^{35}$ and exposure to diethylstilboestrol during pregnancy ${ }^{36}$ and for both suicide and suicide attempt for bereavement stress during preconception (ie, death of a first-degree relative), ${ }^{37}$ mother hypertensive disease (pooled OR suicide 1.09, 0.69-1.72, $\mathrm{n}=2$ studies; HR suicide attempt 1.27, 1.00-1.63) ${ }^{16}$ mother's antenatal depressive mood, ${ }^{38}$ and unwanted pregnancy. ${ }^{38}$ It is worth noting, however, that these comparisons were based on relatively few events.

We found high heterogeneity for most pooled estimates. Meta-regression suggested that 36 to $100 \%$ of this heterogeneity could be explained by the age at follow-up ( $\leq 30$ years versus $>30$ years), but accounting for this factor would not alter our results (appendix). No heterogeneity was explained by study design, and differences in the 
categorization of the exposure variables. When single studies explaining the remaining heterogeneity were removed, the pooled estimate did not change (appendix).

Subgroup analyses, although based on a small number of studies, suggested that associations of maternal age and single motherhood were more pronounced among studies with shorter follow-up ( $\leq 30$ years), whereas associations for birth order, paternal age and parental education were more pronounced among studies with longer follow-up (>30 years) (Figure 5). For all comparisons, we found little evidence that publication bias could have influenced our results (appendix). Sensitivity analyses suggested that confounding factors are unlikely to explain the reported associations.

\section{Discussion}

To our knowledge, this is the first systematic review and meta-analysis summarizing the available evidence of the inutero and perinatal influences on suicide. We showed that in-utero and perinatal influences, especially family/parental characteristics, socioeconomic characteristics, and indices of foetal growth, are associated with increased suicide risk several decades later. Although such findings are consistent with DOHaD hypothesis, ${ }^{4,10}$ in-utero and perinatal factors are generally absent from most of the current models of suicide. Integrating the contribution of these early-life factors would improve our understanding of the aetiology of suicide and inform population-based suicide prevention efforts. However, some important issues remain to be clarified in future research.

First, many risk factors such as obstetric characteristics and conditions/exposures during pregnancy remain under-investigated. Although single studies were of high quality, additional evidence is needed to draw firm conclusions about their role on the aetiology of suicide. Moreover, no data was available for several other potentially relevant factors, such as maternal psychopathology, substance use, infections, and birth complications, that were shown to contribute to the aetiology of other mental disorders. ${ }^{14}$

Second, suicide attempt and suicidal ideation were under-investigated outcomes. It is important for future studies to test whether early-life factors associated with suicide are similarly associated with non-fatal suicide attempt. Our meta-analysis suggests that while some associations are similar for suicide and suicide attempt (eg, mother's young age), for other factors (eg, birth order) the available evidence does not allow us to draw firm conclusions. Additionally, as the literature showed that many childhood/adolescence risk factors for suicidal thoughts differ from those for suicidal acts, ${ }^{39}$ future studies should clarify whether this applies to in-utero and perinatal influences as well. 
Given the low number of studies investigating suicidal ideation as an outcome, additional evidence on this point is needed.

Third, future studies are needed to establish the causality of associations. Although most studies adjusted for relevant confounding factors, causation cannot be established as unmeasured factors may account for observed associations. ${ }^{40}$ For example, associations of adverse maternal conditions with suicide risk could be due to parental psychiatric disorders influencing both adverse maternal conditions (eg, teenage pregnancy, single motherhood) and mental health disorders in the offspring. Among the 42 included studies, only 8 investigated the confounding role of parental psychopathology (appendix). Although it is difficult to reach firm conclusions, we observed that associations between early-life factors and suicide outcomes persisted after adjustment for parental mental disorders, including in sibling designs. This is in line with findings from a recent study that indicates that parental psychopathology is unlikely to fully explain the association between early-life influences and mental disorders. ${ }^{41}$ Additionally, although experimental studies are unfeasible or unethical, quasi-experimental approaches, based on instrumental variables or twin/sibling designs, are available. ${ }^{40,42}$ Few such studies were identified in this review, and provided evidence suggesting that the association of birth order and maternal age on suicide was causal. ${ }^{26,27}$ However, one study reported that the association between low birthweight and suicide attempt was fully attenuated using a sibling design. ${ }^{43}$ These quasi-experimental studies account for factors that sibling share within the family, including parental psychopathology. Future studies should use such designs to prompt causal conclusions.

Fourth, suicide rather than being a single condition, is a behaviour resulting from a combination of vulnerability factors and immediate precipitant factors. Therefore, the observed associations are likely to reflect both the influence of early risk factors on mental disorder strongly associated with suicide (eg, schizophrenia, major depression), and the influence of early risk factors on behaviours, such as impulsive-aggression, that are specifically associated with suicide. ${ }^{44}$ Therefore, future studies are needed to clarify whether the in-utero and perinatal risk factors for suicide identified in our meta-analysis are also related to adolescence/adult psychiatric disorders comorbid with suicide, or whether they are specific to suicide. The association between family and maternal characteristics at child birth and suicide risk is consistent with studies that found: (i) a negative dose-response association of higher birth order with adult psychiatric admissions ${ }^{45}$ and mental illness, ${ }^{29}$ (ii) associations of young mother's age and single mother household with behavioural and mental health problems, ${ }^{46,47}$ and (iii) the association between socioeconomic adversity in childhood and adverse social, health, and mortality outcomes. ${ }^{48}$ However, the absence of association between advanced father's age and suicide risk differs from the documented association between young paternal age 
with behaviour syndromes and psychosis and advanced paternal age with pervasive developmental disorders/autism spectrum disorder. ${ }^{49}$ On the other hand, one study suggested an increased risk of suicide attempt for individuals born from a father aged $>45$ years, ${ }^{30}$ which calls for further investigations to ascertain whether advanced paternal age is specifically linked with non-fatal suicidal behaviours. Similarly, our meta-analysis also provides evidence for an association between low birthweight and risk for suicide, suicide attempt, and suicidal ideation that is consistent with what has been reported for ADHD, autism, ${ }^{43}$ and schizophrenia, ${ }^{14}$ but inconsistent with a meta-analysis that failed to report an association with depression. ${ }^{50}$

Finally, the mechanisms underlying associations between in-utero/perinatal factors and suicide should be clarified. First, factors such as young mother's age, teenage mothers, single motherhood, and low socioeconomic position at birth may reflect an adverse psychosocial environment which increased level of stress in pregnant mothers. ${ }^{9}$ Maternal stress may affect foetal brain development through epigenetic mechanisms (eg, alterations in the glucocorticoid receptor and the central corticotrophin hormone) or gene-by-environment interactions mechanisms (eg, via Oxytocin pathways) ${ }^{51}$ leading to persistent neurobiological alterations of the hypothalamic-pituitary-adrenal axis. ${ }^{4,52,53}$ Second, socioeconomic adversity in the prenatal and perinatal period is likely to continue during childhood (limiting children's access to social capital, educational resources, and adequate cognitive stimulation) and adulthood, yielding an increased risk for mental disorder, adverse experiences (including trauma), low social support, and suicide risk. ${ }^{54}$ Third, inadequate maternal nutrition in pregnancy due to low family resources, or impoverished foetal nutrition of later-born children due to depletion of maternal nutritional reserves during prior pregnancies (thrifty-phenotype hypothesis), ${ }^{55}$ may be associated with future mental disorders increasing the suicide risk. Therefore, knowledge of these mechanisms is of utmost importance as they may inform population-based prevention interventions targeting such mechanisms.

This study is based on a systematic literature search with no date limit, and the good quality of the included studies positively affected the quality of the meta-analytic results. Despite these strengths, this study has limitations. First, the large majority of the included studies came from high-income countries, especially from Northern-Europe, with under-representation of low and middle-income countries. This is a fundamental gap that needs to be addressed, as the investigated associations might be different in other socio-economic contexts. Second, our meta-analysis only reported crude associations, therefore the pooled ORs might have overestimated the association between in-utero and perinatal risk factors and suicide risk because of inadequate adjustment for confounding. Third, although most heterogeneity has been explained by differences in age at follow-up across studies, data were not sufficient to conduct 
detailed subgroup analyses. Fourth, it was not possible to investigate sex differences. Finally, unpublished studies were not included in our analyses, which might have generated bias.

In conclusion, the available evidence suggests that prenatal and perinatal characteristics are associated with increased suicide risk during the life course, with some differences between suicide-related outcomes (ie, suicide mortality, suicide attempt, and suicidal ideation) that need to be further investigated. These findings emphasize the role of conception and pregnancy as crucial periods for disease prevention from a public health perspective.

\section{Authors' contribution}

MO, DG, SRD, GT, MCG designed the study; JB elaborate the search strategy and performed the initial search; MO, DB, and MCG performed study selection and quality assessment; MO performed statistical analyses and wrote the first draft of the manuscript; MCG supervised the study; all authors critical reviewed the manuscript and contribute to data interpretation.

\section{Conflict of interest statement}

The authors declare no conflict of interest.

\section{Acknowledgements}

This project has received funding from the EU's Horizon 2020 research and innovation programme under the Marie Skłodowska-Curie grant agreement no. 793396. DG is supported by the National Institute of Health Research (NIHR) Biomedical Research Centre at University Hospitals Bristol National Health Service Foundation Trust and the University of Bristol, UK. The views expressed in this publication are those of the author(s) and not necessarily those of the NHS, the NIHR or the Department of Health and Social Care. M-CG is a fellow of the Fonds de Recherche en Santé du Québec (FRSQ) and is supported by the American Foundation for Suicide Prevention. GT holds a Canada Research Chair (Tier 1) and a NARSAD Distinguished Investigator Award and is supported by grants from the Canadian Institutes of Health Research (FDN148374 and EGM141899). M-CG and GT are supported by the FRQS through the Quebec Network on Suicide, Mood Disorders and Related Disorders. We thank Christine Neilson, University of Manitoba, for peer review of the MEDLINE search strategy. 


\section{References}

1 WHO | Suicide prevention. WHO. http://www.who.int/mental_health/suicide-prevention/en/ (accessed Aug 22, 2018).

2 Goldman-Mellor SJ, Caspi A, Harrington H, et al. Suicide attempt in young people: a signal for long-term health care and social needs. JAMA Psychiatry 2014; 71: 119-27.

3 Franklin JC, Ribeiro JD, Fox KR, et al. Risk Factors for Suicidal Thoughts and Behaviors: A Meta-Analysis of 50 Years of Research. Psychol Bull 2016; published online Nov 14. DOI:10.1037/bul0000084.

4 Turecki G, Ernst C, Jollant F, Labonté B, Mechawar N. The neurodevelopmental origins of suicidal behavior. Trends Neurosci 2012; 35: 14-23.

5 Gluckman PD, Hanson MA, Mitchell MD. Developmental origins of health and disease: reducing the burden of chronic disease in the next generation. Genome Med 2010; 2: 14.

6 Bateson P, Barker D, Clutton-Brock T, et al. Developmental plasticity and human health. Nature 2004; 430: 419-21.

7 Fleming TP, Watkins AJ, Velazquez MA, et al. Origins of lifetime health around the time of conception: causes and consequences. The Lancet 2018; 391: 1842-52.

8 Stephenson J, Heslehurst N, Hall J, et al. Before the beginning: nutrition and lifestyle in the preconception period and its importance for future health. The Lancet 2018; 391: 1830-41.

9 O'Donnell KJ, Meaney MJ. Fetal Origins of Mental Health: The Developmental Origins of Health and Disease Hypothesis. Am J Psychiatry 2016; : appiajp201616020138.

10 Gunnell D, Lewis G. Studying suicide from the life course perspective: implications for prevention. $B r J$ Psychiatry J Ment Sci 2005; 187: 206-8.

11 Rinaudo P, Wang E. Fetal programming and metabolic syndrome. Annu Rev Physiol 2012; 74: 107-30.

12 Osmond C, Barker DJ, Winter PD, Fall CH, Simmonds SJ. Early growth and death from cardiovascular disease in women. BMJ 1993; 307: 1519-24.

13 Gluckman PD, Hanson MA, Cooper C, Thornburg KL. Effect of In Utero and Early-Life Conditions on Adult Health and Disease. N Engl J Med 2008; 359: 61-73.

14 Jones PB, Rantakallio P, Hartikainen AL, Isohanni M, Sipila P. Schizophrenia as a long-term outcome of pregnancy, delivery, and perinatal complications: a 28-year follow-up of the 1966 north Finland general population birth cohort. Am J Psychiatry 1998; 155: 355-64.

$15 \mathrm{Lim}$ KX, Liu C-Y, Schoeler T, et al. The role of birth weight on the causal pathway to child and adolescent ADHD symptomatology: a population-based twin differences longitudinal design. $J$ Child Psychol Psychiatry; 0. DOI:10.1111/jcpp.12949.

16Mittendorfer-Rutz E, Rasmussen F, Wasserman D. Restricted fetal growth and adverse maternal psychosocial and socioeconomic conditions as risk factors for suicidal behaviour of offspring: a cohort study. The Lancet 2004; 364: 1135-40.

17Cnattingius S, Svensson T, Granath F, Iliadou A. Maternal smoking during pregnancy and risks of suicidal acts in young offspring. Eur J Epidemiol 2011; 26: 485-92. 
18 Geoffroy M-C, Gunnell D, Power C. Prenatal and childhood antecedents of suicide: 50-year follow-up of the 1958 British Birth Cohort study. Psychol Med 2014; 44: 1245-56.

19 Osler M, Nybo Andersen A-M, Nordentoft M. Impaired childhood development and suicidal behaviour in a cohort of Danish men born in 1953. J Epidemiol Community Health 2008; 62: 23-8.

20 Stroup DF, Berlin JA, Morton SC, et al. Meta-analysis of observational studies in epidemiology: a proposal for reporting. Meta-analysis Of Observational Studies in Epidemiology (MOOSE) group. JAMA 2000; 283: 2008-12.

21 Wells G, Shea B, O’Connell D, et al. The Newcastle-Ottawa Scale (NOS) for assessing the quality of nonrandomised studies

in meta-analyses.

2012. http://www.ohri.ca/programs/clinical_epidemiology/oxford.asp (accessed Feb 17, 2018).

22 DerSimonian R, Laird N. Meta-analysis in clinical trials. Control Clin Trials 1986; 7: 177-88.

23 Higgins JPT, Thompson SG. Quantifying heterogeneity in a meta-analysis. Stat Med 2002; 21: 1539-58.

24Egger M, Davey Smith G, Schneider M, Minder C. Bias in meta-analysis detected by a simple, graphical test. BMJ 1997; 315: 629-34.

25Duval S, Tweedie R. Trim and fill: A simple funnel-plot-based method of testing and adjusting for publication bias in meta-analysis. Biometrics 2000; 56: 455-63.

26Bjørngaard JH, Bjerkeset O, Vatten L, Janszky I, Gunnell D, Romundstad P. Maternal age at child birth, birth order, and suicide at a young age: a sibling comparison. Am J Epidemiol 2013; 177: 638-44.

27 Rostila M, Saarela J, Kawachi I. Birth order and suicide in adulthood: evidence from Swedish population data. Am J Epidemiol 2014; 179: 1450-7.

28Chen Y-Y, Gunnell D, Lu C-L, Chang S-S, Lu T-H, Li C-Y. Perinatal risk factors for suicide in young adults in Taiwan. Int J Epidemiol 2013; 42: 1381-9.

29 Geoffroy M-C, Gunnell D, Clark C, Power C. Are early-life antecedents of suicide mortality associated with psychiatric disorders and suicidal ideation in midlife? Acta Psychiatr Scand 2018; 137: 116-24.

30D'Onofrio BM, Rickert ME, Frans E, et al. Paternal age at childbearing and offspring psychiatric and academic morbidity. JAMA Psychiatry 2014; 71: 432-8.

31 Fergusson DM, Woodward LJ, Horwood LJ. Risk factors and life processes associated with the onset of suicidal behaviour during adolescence and early adulthood. Psychol Med 2000; 30: 23-39.

32 Page A, Lewis G, Kidger J, et al. Parental socio-economic position during childhood as a determinant of self-harm in adolescence. Soc Psychiatry Psychiatr Epidemiol 2014; 49: 193-203.

33 Nomura Y, Brooks-Gunn J, Davey C, Ham J, Fifer WP. The role of perinatal problems in risk of co-morbid psychiatric and medical disorders in adulthood. Psychol Med 2007; 37: 1323-34.

34Ekblad M, Gissler M, Lehtonen L, Korkeila J. Prenatal Smoking Exposure and the Risk of Psychiatric Morbidity Into Young Adulthood. Arch Gen Psychiatry 2010; 67: 841-9.

35 Neugebauer R, Reuss ML. Association of maternal, antenatal and perinatal complications with suicide in adolescence and young adulthood. Acta Psychiatr Scand 1998; 97: 412-8. 
36 Verdoux H, Ropers J, Costagliola D, Clavel-Chapelon F, Paoletti X. Serious psychiatric outcome of subjects prenatally exposed to diethylstilboestrol in the E3N cohort study. Psychol Med 2007; 37: 131522.

37Class QA, Abel KM, Khashan AS, et al. Offspring psychopathology following preconception, prenatal and postnatal maternal bereavement stress. Psychol Med 2014; 44: 71-84.

38 Alaräisänen A, Miettunen J, Pouta A, Isohanni M, Räsänen P, Mäki P. Ante- and perinatal circumstances and risk of attempted suicides and suicides in offspring: the Northern Finland birth cohort 1966 study. Soc Psychiatry Psychiatr Epidemiol 2012; 47: 1783-94.

39 Mars B, Heron J, Klonsky ED, et al. What distinguishes adolescents with suicidal thoughts from those who have attempted suicide? A population-based birth cohort study. J Child Psychol Psychiatry 2018; published online March 1. DOI:10.1111/jcpp.12878.

40 Gage SH, Munafò MR, Davey Smith G. Causal Inference in Developmental Origins of Health and Disease (DOHaD) Research. Annu Rev Psychol 2016; 67: 567-85.

41 McGrath JJ, Petersen L, Agerbo E, Mors O, Mortensen PB, Pedersen CB. A Comprehensive Assessment of Parental Age and Psychiatric Disorders. JAMA Psychiatry 2014; 71: 301-9.

42 Pingault J-B, O'Reilly PF, Schoeler T, Ploubidis GB, Rijsdijk F, Dudbridge F. Using genetic data to strengthen causal inference in observational research. Nat Rev Genet 2018; 19: 566-80.

43Class QA, Rickert ME, Larsson H, Lichtenstein P, D'Onofrio BM. Fetal growth and psychiatric and socioeconomic problems: population-based sibling comparison. Br J Psychiatry J Ment Sci 2014; 205: 35561.

44Gunnell D. A Population Health Perspective on Suicide Research and

Prevention. Crisis 2015; 36: $155-60$.

45 Riordan DV, Morris C, Hattie J, Stark C. Family size and perinatal circumstances, as mental health risk factors in a Scottish birth cohort. Soc Psychiatry Psychiatr Epidemiol 2012; 47: 975-83.

46 Aitken Z, Hewitt B, Keogh L, LaMontagne AD, Bentley R, Kavanagh AM. Young maternal age at first birth and mental health later in life: Does the association vary by birth cohort? Soc Sci Med 1982 2016; 157: 9-17.

47 Tremblay RE, Vitaro F, Côté SM. Developmental Origins of Chronic Physical Aggression: A Bio-PsychoSocial Model for the Next Generation of Preventive Interventions. Annu Rev Psychol 2018; 69: 383-407.

48 Mikkonen HM, Salonen MK, Häkkinen A, et al. The lifelong socioeconomic disadvantage of single-mother background - the Helsinki Birth Cohort study 1934-1944. BMC Public Health 2016; 16. DOI:10.1186/s12889-016-3485-z.

49 Merikangas AK, Calkins ME, Bilker WB, Moore TM, Gur RC, Gur RE. Parental Age and Offspring Psychopathology in the Philadelphia Neurodevelopmental Cohort. J Am Acad Child Adolesc Psychiatry 2017; 56: 391-400.

50 Wojcik W, Lee W, Colman I, Hardy R, Hotopf M. Foetal origins of depression? A systematic review and meta-analysis of low birth weight and later depression. Psychol Med 2013; 43: 1-12.

51 Toepfer P, Heim C, Entringer S, Binder E, Wadhwa P, Buss C. Oxytocin pathways in the intergenerational transmission of maternal early life stress. Neurosci Biobehav Rev 2017; 73: 293-308. 
52 Turecki G, Meaney MJ. Effects of the Social Environment and Stress on Glucocorticoid Receptor Gene Methylation: A Systematic Review. Biol Psychiatry 2014; published online Dec 13. DOI:10.1016/j.biopsych.2014.11.022.

53 Carballo JJ, Currier D, Figueroa AE, et al. Neurobiological underpinnings of suicidal behavior: Integrating data from clinical and biological studies. Eur J Psychiatry 2009; 23: 243-59.

54 Grantham-McGregor S, Cheung YB, Cueto S, Glewwe P, Richter L, Strupp B. Developmental potential in the first 5 years for children in developing countries. The Lancet 2007; 369: 60-70.

55 Vaag AA, Grunnet LG, Arora GP, Brøns C. The thrifty phenotype hypothesis revisited. Diabetologia 2012; 55: $2085-8$.

56Easey KE, Mars B, Pearson R, Heron J, Gunnell D. Association of birth order with adolescent mental health and suicide attempts: a population-based longitudinal study. Eur Child Adolesc Psychiatry 2019; published online Jan 2. DOI:10.1007/s00787-018-1266-1.

57 Li CI, Daling JR, Emanuel I. Birthweight and risk of overall and cause-specific childhood mortality. Paediatr Perinat Epidemiol 2003; 17: 164-70.

58Fergusson DM, Woodward LJ. Maternal age and educational and psychosocial outcomes in early adulthood. J Child Psychol Psychiatry 1999; 40: 479-89.

59 Sørensen HJ, Mortensen EL, Wang AG, Juel K, Silverton L, Mednick SA. Suicide and mental illness in parents and risk of suicide in offspring: a birth cohort study. Soc Psychiatry Psychiatr Epidemiol 2009; 44: $748-51$.

60 Christoffersen MN, Poulsen HD, Nielsen A. Attempted suicide among young people: risk factors in a prospective register based study of Danish children born in 1966. Acta Psychiatr Scand 2003; 108: 350-8.

61 Mok PLH, Antonsen S, Pedersen CB, Webb RT. Younger or older parental age and risk of suicidality, premature death, psychiatric illness, and criminality in offspring. $J$ Affect Disord 2017; 208: 130-8.

62 Saarela J, Cederström A, Rostila M. Birth order and mortality in two ethno-linguistic groups: Registerbased evidence from Finland. Soc Sci Med 1982 2016; 158: 8-13.

63 Lahti M, Eriksson JG, Heinonen K, et al. Maternal Grand Multiparity and the Risk of Severe Mental Disorders in Adult Offspring. PloS One 2014; 9: e114679.

64 Lahti M, Eriksson JG, Heinonen K, et al. Late preterm birth, post-term birth, and abnormal fetal growth as risk factors for severe mental disorders from early to late adulthood. Psychol Med 2015; 45: 985-99.

65 Dykxhoorn J, Hatcher S, Roy-Gagnon M-H, Colman I. Early life predictors of adolescent suicidal thoughts and adverse outcomes in two population-based cohort studies. PloS One 2017; 12: e0183182.

66 Miller B, Alaräisänen A, Miettunen J, et al. Advanced paternal age, mortality, and suicide in the general population. J Nerv Ment Dis 2010; 198: 404-11.

67 Sauvola A, Räsänen PK, Joukamaa MI, Jokelainen J, Järvelin M-R, Isohanni MK. Mortality of young adults in relation to single-parent family backgroundA prospective study of the Northern Finland 1966 birth cohort. Eur J Public Health 2001; 11: 284-6.

68 Gravseth HM, Mehlum L, Bjerkedal T, Kristensen P. Suicide in young Norwegians in a life course perspective: population-based cohort study. J Epidemiol Community Health 2010; 64: 407-12. 
69 Risnes KR, Pape K, Bjørngaard JH, Moster D, Bracken MB, Romundstad PR. Premature Adult Death in Individuals Born Preterm: A Sibling Comparison in a Prospective Nationwide Follow-Up Study. PLOS ONE 2016; 11: e0165051.

70 Barros FC, Matijasevich A, Santos IS, et al. Social inequalities in mental disorders and substance misuse in young adults : A birth cohort study in Southern Brazil. Soc Psychiatry Psychiatr Epidemiol 2018; 53: 717-26.

71 Riordan DV, Selvaraj S, Stark C, Gilbert JSE. Perinatal circumstances and risk of offspring suicide. Birth cohort study. Br J Psychiatry J Ment Sci 2006; 189: 502-7.

72 Young R, Riordan V, Stark C. Perinatal and psychosocial circumstances associated with risk of attempted suicide, non-suicidal self-injury and psychiatric service use. A longitudinal study of young people. $B M C$ Public Health 2011; 11: 875.

73 D’Onofrio BM, Class QA, Rickert ME, Larsson H, Långström N, Lichtenstein P. Preterm birth and mortality and morbidity: a population-based quasi-experimental study. JAMA Psychiatry 2013; 70: 123140.

74Ekéus C, Olausson PO, Hjern A. Psychiatric morbidity is related to parental age: a national cohort study. Psychol Med 2006; 36: 269-76.

75 Mittendorfer-Rutz E, Wasserman D, Rasmussen F. Fetal and childhood growth and the risk of violent and non-violent suicide attempts: a cohort study of 318,953 men. J Epidemiol Community Health 2008; 62: $168-73$.

76 Niederkrotenthaler T, Rasmussen F, Mittendorfer-Rutz E. Perinatal conditions and parental age at birth as risk markers for subsequent suicide attempt and suicide: a population based case-control study. Eur $J$ Epidemiol 2012; 27: 729-38.

77von Borczyskowski A, Lindblad F, Vinnerljung B, Reintjes R, Hjern A. Familial factors and suicide: an adoption study in a Swedish National Cohort. Psychol Med 2011; 41: 749-58.

78 Steck N, Egger M, Schimmelmann BG, Kupferschmid S, Swiss National Cohort. Suicide in adolescents: findings from the Swiss National cohort. Eur Child Adolesc Psychiatry 2017; published online June 29. DOI:10.1007/s00787-017-1019-6.

79Danziger PD, Silverwood R, Koupil I. Fetal growth, early life circumstances, and risk of suicide in late adulthood. Eur J Epidemiol 2011; 26: 571-81. 


\section{Research in context}

\section{Evidence before this study}

We systematically searched Medline without data and language limitations up to March 6, 2018, using the following keywords: (suicid* OR "suicide attempt" OR "attempted suicide" OR "suicidal ideation" OR "suicide thoughts" OR "suicidal behavior" OR "suicidal behaviours" OR "completed suicide" OR "suicide risk" OR "suicidality") AND ("birth order" OR "parity" OR "multiparity" OR "family size" OR "sibship size" OR "number of siblings" OR "birth weight" OR "underweight" OR "maternal age" OR "mother age" OR "paternal age" OR "father age" OR "parent* age" OR "foetal fetal growth" OR "fetal growth" OR "early life" OR "early-life" OR perinatal OR prenatal) AND (longitudinal OR "population-based" OR cohort OR observational OR prospective OR "registry" OR "registerbased"). Most of the retrieved studies investigated risk factors measured during childhood, and a few investigated risk factors during the in-utero and perinatal periods, resulting in 20 relevant studies. No systematic review or metaanalysis was identified. Most studies came from high-quality cohorts and population-based registers. Some studies suggested increased suicide risk for some risk factors (such as increased birth order, low socioeconomic position at birth). However, while similar in quality and design: (i) some studies reported different estimates for the same risk factor; (ii) some studies reported similar estimates (eg, similar Hazard/Odds Ratios) but different confidence intervals, so that only some of the studies could conclude for a statistically significant difference between individuals exposed and non-exposed to the same risk factor; (iii) some studies had different follow-up periods, ie, some extending until adolescence/young adulthood, others extending until adulthood; (iv) almost all studies presented both crude and adjusted estimates, but the choice of the adjustment variables was highly variable across studies; in particular, some studies adjusted for factors occurring between the exposure (eg, low birthweight) and the outcome (eg, suicide), which can bias the estimate of the contribution of the exposure. These differences preclude firm conclusions about the role of these factors on suicide risk.

\section{Added value of this study}

To our knowledge, this is the first systematic review and meta-analysis summarizing the available evidence about the in-utero and perinatal influences on suicide. We found that, across the high-quality included studies, family/parental characteristics at child birth (eg, higher birth order, low mother's age, single motherhood), low socioeconomic position (eg, low parental education and socioeconomic status), and restricted foetal growth (eg, low birthweight, small for gestational age) were associated with increased suicide risk. No evidence for an association was found for risk factors such as advanced father's age, low gestational age, obstetric characteristics, and mother's smoking in pregnancy. Moreover, accounting for the participant's age at follow-up explained the heterogeneity across studies for most comparisons, without changing the study conclusions.

\section{Implications of all the available evidence}

Evidence suggests that prenatal and perinatal characteristics are associated with increased suicide risk during the life course, with main influences represented by unfavourable family/parental characteristics and restricted foetal growth. However, more studies are necessary to establish the role of those risk factors on suicide attempt and ideation, extend the evidence to understudied influences, and probe their causal role. 
Table 1. Characteristics of the included studies

\begin{tabular}{|c|c|c|c|c|c|c|c|c|c|}
\hline Sample & Study & $\begin{array}{l}\text { Study } \\
\text { design }\end{array}$ & Level of analysis & $\begin{array}{l}\text { Participants } \\
\text { (n) }\end{array}$ & $\begin{array}{l}\text { Year range } \\
\text { at birth }\end{array}$ & $\begin{array}{l}\text { Year range } \\
\text { at outcome } \\
\text { assessment }\end{array}$ & $\begin{array}{l}\text { Follow- } \\
\text { up } \\
\text { range }\end{array}$ & $\begin{array}{l}\text { Investigated } \\
\text { outcomes }\end{array}$ & $\begin{array}{l}\text { Investigated in-utero and } \\
\text { perinatal factors }\end{array}$ \\
\hline \multicolumn{10}{|l|}{1958 British Birth Cohort } \\
\hline 1958 British Birth Cohort & Geoffroy $2014^{18}$ & Cohort & Whole population & 16470 & 1958 & $1965-2009$ & $7-51$ & Suicide & $\begin{array}{l}\text { Birth order, maternal age, } \\
\text { SES, gestational age, birth } \\
\text { weight, smoking in } \\
\text { pregnancy }\end{array}$ \\
\hline 1958 British Birth Cohort & Geoffroy $2018^{29}$ & Cohort & Whole population & 8905 & 1958 & 2003 & $45-45$ & Ideation & $\begin{array}{l}\text { Birth order, maternal age, } \\
\text { SES, birth weight }\end{array}$ \\
\hline \multicolumn{10}{|l|}{ ALSPAC } \\
\hline & Easey $2019^{56}$ & Cohort & Whole population & 2571 & 1991-1992 & up to 2008 & up to 16 & Attempt & Birth order \\
\hline & Page $2014^{32}$ & Cohort & Whole population & 1806 & 1991-1992 & $2007-2009$ & $16-18$ & Attempt & SES, maternal education \\
\hline Born in Washington State, US, in 1968-96 & Li $2003^{57}$ & Register & Whole population & 23882 & 1968-1996 & NA & $1-19$ & Suicide & Birthweight \\
\hline \multicolumn{10}{|l|}{ CHDS } \\
\hline CDHS & Fergusson $1999^{58}$ & Cohort & Whole population & 1025 & 1977-1998 & $1992-1996$ & up to 18 & Attempt & Maternal age \\
\hline CDHS & Fergusson $2000^{31}$ & Cohort & Whole population & 1265 & 1977-1998 & 1992-1998 & up to 21 & $\begin{array}{l}\text { Attempt, } \\
\text { ideation }\end{array}$ & $\begin{array}{l}\text { Maternal age, single mother, } \\
\text { SES, maternal education }\end{array}$ \\
\hline Copenhagen Perinatal Cohort 1959-1961 & Sorensen $2009^{59}$ & Register & Whole population & 7177 & $1959-1961$ & $1969-2005$ & $10-46$ & Suicide & SES \\
\hline \multicolumn{10}{|l|}{ Danish born in 1966-1996 } \\
\hline Danish born in 1966 & Christofferssen $2003^{60}$ & Register & Whole population & 84765 & 1966 & $1981-1993$ & $14-27$ & Attempt & Maternal age \\
\hline Danish born in 1966-1996 & Mok $2017^{61}$ & Register & Whole population & 1793681 & 1966-1996 & $1981-2006$ & $15-40$ & Suicide & Maternal age, paternal age \\
\hline Danish Metropolit Cohort & Osler $2008^{19}$ & Cohort & Whole population & 9359 & 1953 & 1972-2002 & $19-49$ & $\begin{array}{l}\text { Suicide, } \\
\text { attempt }\end{array}$ & $\begin{array}{l}\text { Single mother, SES, } \\
\text { birthweight }\end{array}$ \\
\hline E3N Cohort 1990 & Verdoux $2007^{36}$ & Cohort & Sibling design & 3127 & NA & up to 2004 & NA & Suicide & $\begin{array}{l}\text { Exposure to } \\
\text { diethylstilboestrol }\end{array}$ \\
\hline \multicolumn{10}{|l|}{ Finnish born in 1922-1989 } \\
\hline Finnish born in $1922-1987$ & Saarela $2016^{62}$ & Register & Sibling design & 254059 & $1922-1987$ & $1987-2011$ & $0-89$ & Suicide & Birth order \\
\hline Finnish born in $1987-1989$ & Ekblad $2010^{34}$ & Register & Whole population & 179869 & $1987-1989$ & $1987-2007$ & $0-20$ & Suicide & Smoking in pregnancy \\
\hline \multicolumn{10}{|l|}{ Helsinki Birth Cohort Study 1934-1944 } \\
\hline Helsinki Birth Cohort Study 1934-1944 & Lahti $2014^{63}$ & Register & Whole population & 13242 & 1934-1944 & $1969-2010$ & $24-76$ & $\begin{array}{l}\text { Suicide, } \\
\text { attempt }\end{array}$ & Birth order \\
\hline Helsinki Birth Cohort Study 1934-1944 & Lahti $2015^{64}$ & Register & Whole population & 12597 & 1934-1944 & $1969-2010$ & $25-76$ & $\begin{array}{l}\text { Suicide, } \\
\text { attempt }\end{array}$ & Gestational age, SGA \\
\hline $\begin{array}{l}\text { Johns Hopkins Collaborative Perinatal } \\
\text { Study }\end{array}$ & Nomura $2007^{33}$ & Cohort & Whole population & 1525 & $1960-1964$ & 1992-1994 & $27-33$ & Ideation & $\begin{array}{l}\text { Gestational age, birthweight, } \\
\text { head circumference, APGAR }\end{array}$ \\
\hline $\begin{array}{l}\text { National Longitudinal Survey of Children } \\
\text { and Youth } \\
\text { Northern Finland Birth Cohort } 1966\end{array}$ & Dykxhoorn $2017^{65}$ & Cohort & Whole population & 6388 & 1994-2009 & NA & $12-25$ & Ideation & $\begin{array}{l}\text { Maternal age, prenatal care } \\
\text { after } 20 \text { weeks of gestation }\end{array}$ \\
\hline Northern Finland Birth Cohort 1966 & Alaräisänen $2012^{38}$ & Cohort & Whole population & 10742 & 1966 & $1967-2005$ & up to 39 & $\begin{array}{l}\text { Suicide, } \\
\text { attempt }\end{array}$ & $\begin{array}{l}\text { Birth order, maternal age, } \\
\text { single mother, SES, antenatal } \\
\text { depression, unwanted } \\
\text { pregnancy }\end{array}$ \\
\hline
\end{tabular}


Northern Finland Birth Cohort 1966

Northern Finland Birth Cohort 1966 Norwegians born in 1967-1997

Norwegians born in 1967-1996

Norwegians born in 1967-1976

Norwegians born in 1967-1997

Pelotas Birth Cohort

Scottish born in 1969-1988

Scottish born in 1969-1986

Scottish born in 1969-1986

Scottish longitudinal survey of young people

\section{Swedish born in 1932-1997}

Swedish born in 1973-1997

Swedish born in 1973-1997

Swedish born in 1983-1996

Swedish born in 1973-1997

Swedish born in 1973-1997

Swedish born in 1973-1979

Swedish born in 1973-1980

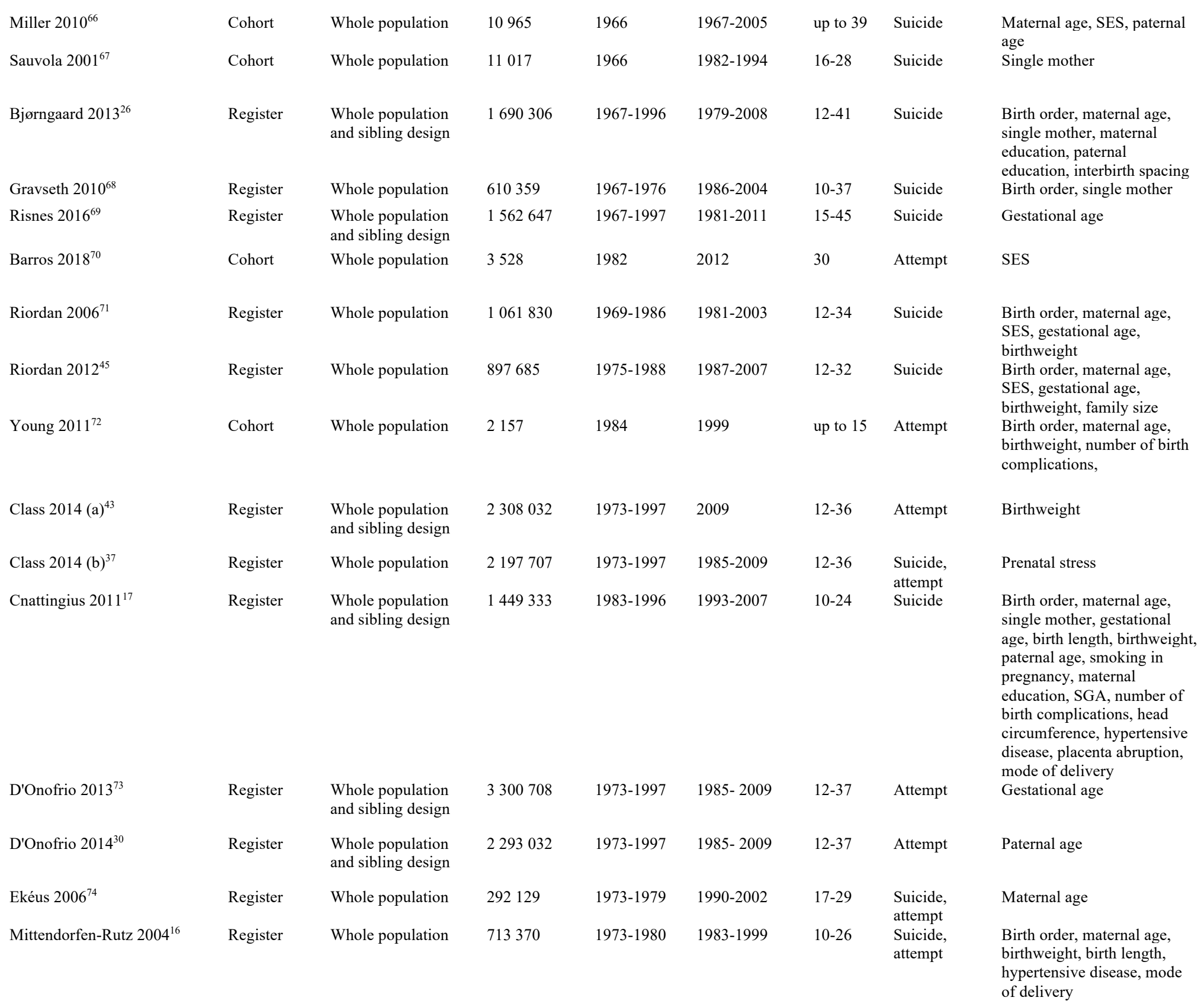




\begin{tabular}{|c|c|c|c|c|c|c|c|c|c|}
\hline Swedish born in 1973-1980 & Mittendorfen-Rutz $2008^{75}$ & Register & Whole population & 318953 & 1973-1980 & 1991-1999 & $\begin{array}{l}18 / 19- \\
26\end{array}$ & Attempt & $\begin{array}{l}\text { Gestational age, birthweight, } \\
\text { birth length }\end{array}$ \\
\hline Swedish born in 1973-1983 & Niederkrotenthaler $2012^{76}$ & Register & Case-control & 14976 & 1973-1983 & 1983-2004 & $10-31$ & $\begin{array}{l}\text { Suicide, } \\
\text { attempt }\end{array}$ & $\begin{array}{l}\text { Birth order, maternal age, } \\
\text { gestational age, birthweight, } \\
\text { paternal age, SGA, birth } \\
\text { length }\end{array}$ \\
\hline Swedish born in 1932-1980 & Rostila $2014^{27}$ & Register & Sibling design & 102824 & $1932-1980$ & 1981-2002 & up to 70 & Suicide & Birth order, maternal age \\
\hline Swedish born in 1946-1968 & Von Borczyskowski $2010^{77}$ & Register & Whole population & 2936224 & 1946-1968 & $1987-2001$ & $19-55$ & Suicide & $\begin{array}{l}\text { Maternal age, SES, paternal } \\
\text { age }\end{array}$ \\
\hline Swiss National Cohort & Steck $2018^{78}$ & Register & Whole population & 2395677 & $1990-2000$ & $2000-2008$ & $10-18$ & Suicide & $\begin{array}{l}\text { Birth order, maternal age } \\
\text { single mother, SES, paternal } \\
\text { age, parental education }\end{array}$ \\
\hline Taiwaneses born in 1978-1993 & Chen $2013^{28}$ & Register & Case-control & 123504 & $1978-1993$ & 1993-2008 & $15-30$ & Suicide & $\begin{array}{l}\text { Birth order, maternal age, } \\
\text { single mother, maternal } \\
\text { education, paternal education }\end{array}$ \\
\hline Uppsala University Hospital in 1915-1929 & Danziger $2011^{79}$ & Register & Whole population & 11650 & $1915-1929$ & $1960-2002$ & $31-87$ & Suicide & $\begin{array}{l}\text { Birth order, maternal } \\
\text { education, single mother, } \\
\text { SES, gestational age, birth } \\
\text { weight, SGA }\end{array}$ \\
\hline
\end{tabular}

ALSPAC, Avon Longitudinal Study of Parents and Children; CHDS, Christchurch Health and Development Study; NA, not available; SGA, Small for gestational age; SES, Socioeconomic status 
Table 2. Quality assessment according to the Newcastle-Ottawa Scale criteria

\begin{tabular}{|c|c|c|c|c|c|c|c|c|c|c|}
\hline \multirow[b]{2}{*}{ Sample } & \multirow[b]{2}{*}{ Study and year } & \multicolumn{4}{|l|}{ Selection } & \multirow{2}{*}{$\begin{array}{l}\text { Comparability } \\
\text { Case/control } \\
\text { comparability (0- } \\
\text { 2) }\end{array}$} & \multicolumn{3}{|l|}{ Outcome } & \multirow[b]{2}{*}{$\begin{array}{l}\text { Qualit } \\
\text { y score } \\
(0-9)\end{array}$} \\
\hline & & $\begin{array}{l}\text { Representa } \\
\text { tiv } \\
\text { eness (0-1) }\end{array}$ & $\begin{array}{l}\text { Selection } \\
\text { non } \\
\text { exposed }(0- \\
\text { 1) } \\
\end{array}$ & $\begin{array}{l}\text { Ascertainm } \\
\text { ent } \\
\text { exposure } \\
(0-1) \\
\end{array}$ & $\begin{array}{l}\text { Outcome not } \\
\text { present at } \\
\text { study start (0- } \\
\text { 1) }\end{array}$ & & $\begin{array}{l}\text { Assesse } \\
\text { ment of } \\
\text { outcome } \\
(0-1) \\
\end{array}$ & $\begin{array}{l}\text { Length of } \\
\text { follow-up } \\
(0-1)\end{array}$ & $\begin{array}{l}\text { Adequacy } \\
\text { of follow- } \\
\text { up (0-1) }\end{array}$ & \\
\hline \multicolumn{11}{|l|}{1958 British Birth Cohort } \\
\hline 1958 British Birth Cohort & Geoffroy $2014^{18}$ & 1 & 1 & 0 & 1 & 2 & 1 & 1 & 1 & 8 \\
\hline 1958 British Birth Cohort & Geoffroy $2018^{29}$ & 1 & 1 & 0 & 1 & 2 & 1 & 0 & 0 & 5 \\
\hline ALSPAC & & 1 & 1 & 0 & 1 & 2 & 0 & 1 & 0 & 6 \\
\hline ALSPAC & Page $2014^{32}$ & 1 & 1 & 1 & 1 & 2 & 0 & 1 & 1 & 8 \\
\hline \multicolumn{10}{|l|}{ CHDC } & 8 \\
\hline $\mathrm{CHDC}$ & Fergusson $1999^{58}$ & 1 & 1 & 0 & 1 & 1 & 0 & 1 & 1 & 6 \\
\hline CHDC & Fergusson $2000^{31}$ & 1 & 1 & 0 & 1 & 2 & 0 & 1 & 1 & 7 \\
\hline Copenhagen Perinatal Cohort 1959-1961 & Sorensen $2009^{59}$ & 1 & 1 & 1 & 1 & 1 & 1 & 1 & 1 & 8 \\
\hline \multicolumn{11}{|l|}{ Danish born in 1966-1996 } \\
\hline Danish born in 1966 & Christofferssen $2003^{60}$ & 1 & 1 & 1 & 1 & 2 & 1 & 1 & 1 & 9 \\
\hline Danish born in 1966-1996 & Mok $2017^{61}$ & 1 & 1 & 1 & 1 & 2 & 1 & 1 & 1 & 9 \\
\hline E3N Cohort 1990 & Verdoux $2007^{36}$ & 1 & 1 & 0 & 1 & 1 & 0 & 1 & 1 & 6 \\
\hline \multicolumn{11}{|l|}{ Finnish born in 1922-1989 } \\
\hline Finnish born in $1922-1987$ & Saarela $2016^{62}$ & 1 & 1 & 1 & 1 & 2 & 1 & 1 & 1 & 9 \\
\hline Finnish born in $1987-1989$ & Ekblad $2010^{34}$ & 1 & 1 & 1 & 1 & 2 & 1 & 1 & 1 & 9 \\
\hline \multicolumn{11}{|l|}{ Helsinki Birth Cohort Study 1934-1944 } \\
\hline Helsinki Birth Cohort Study 1934-1944 & Lahti $2014^{63}$ & 1 & 1 & 1 & 1 & 2 & 1 & 1 & 1 & 9 \\
\hline Helsinki Birth Cohort Study 1934-1944 & Lahti $2015^{64}$ & 1 & 1 & 1 & 1 & 2 & 1 & 1 & 1 & 9 \\
\hline Johns Hopkins Collaborative Perinatal Study & Nomura $2007^{33}$ & 1 & 1 & 1 & 1 & 2 & 0 & 1 & 1 & 8 \\
\hline NLSCY & Dykxhoorn $2017^{65}$ & 1 & 1 & 0 & 1 & NA & 0 & 1 & 0 & 4 \\
\hline \multicolumn{11}{|l|}{ Northern Finland Birth Cohort 1966} \\
\hline Northern Finland Birth Cohort 1966 & Alaräisänen $2012^{38}$ & 1 & 1 & 1 & 1 & 2 & 1 & 1 & 1 & 9 \\
\hline Northern Finland Birth Cohort 1966 & Miller $2010^{66}$ & 1 & 1 & 0 & 1 & 2 & 1 & 1 & 1 & 8 \\
\hline Northern Finland Birth Cohort 1966 & Sauvola $2001^{67}$ & 1 & 1 & 0 & 1 & 1 & 1 & 1 & 1 & 7 \\
\hline \multicolumn{11}{|l|}{ Norwegians born in 1967-1997 } \\
\hline Norwegians born in 1967-1996 & Bjørngaard $2013^{26}$ & 1 & 1 & 1 & 1 & 2 & 1 & 1 & 1 & 9 \\
\hline Norwegians born in 1967-1976 & Gravseth $2010^{68}$ & 1 & 1 & 1 & 1 & 1 & 1 & 1 & 1 & 8 \\
\hline Norwegians born in 1967-1997 & Risnes $2016^{69}$ & 1 & 1 & 1 & 1 & 2 & 1 & 1 & 1 & 9 \\
\hline
\end{tabular}


Scottish longitudinal survey of young people

$\begin{array}{ll}1 & 1 \\ 1 & 1 \\ 1 & 1 \\ 1 & 1 \\ 1 & 1 \\ 1 & 1 \\ 1 & 1 \\ 1 & 1 \\ 1 & 1 \\ 1 & 1 \\ 1 & 1 \\ 1 & 1 \\ 1 & 1 \\ 1 & 1 \\ 1 & 1 \\ 1 & 1 \\ 1 & 1\end{array}$

$\begin{array}{lll}1 & 1 & 2 \\ 1 & 1 & 2 \\ 0 & 1 & 2 \\ 1 & 1 & 2 \\ 1 & 1 & 2 \\ 1 & 1 & 2 \\ 1 & 1 & 2 \\ 1 & 1 & 2 \\ 1 & 1 & 2 \\ 1 & 1 & 2 \\ 1 & 1 & 2 \\ 1 & 1 & 2 \\ 1 & 1 & 2 \\ 1 & 1 & 2 \\ 1 & 1 & 2 \\ 1 & 1 & 2 \\ 1 & 1 & 2\end{array}$

\begin{tabular}{lllll}
2 & 1 & 1 & 1 & 9 \\
2 & 1 & 1 & 1 & 9 \\
2 & 0 & 1 & 1 & 7 \\
2 & 1 & 1 & 1 & 9 \\
2 & 1 & 1 & 1 & 9 \\
2 & 1 & 1 & 1 & 9 \\
2 & 1 & 1 & 1 & 9 \\
2 & 1 & 1 & 1 & 9 \\
2 & 1 & 1 & 1 & 9 \\
2 & 1 & 1 & 1 & 9 \\
2 & 1 & 1 & 1 & 9 \\
2 & 1 & 1 & 1 & 9 \\
2 & 1 & 1 & 1 & 9 \\
2 & 1 & 1 & 1 & 9 \\
2 & 1 & 1 & 1 & 9 \\
2 & 1 & 1 & 1 & 9 \\
2 & 1 & 1 & 1 & 9 \\
\hline
\end{tabular}

ALSPAC, Avon Longitudinal Study of Parents and Children; CHDS, Christchurch Health and Development Study; NA, not applicable 
Figure 1. Flow chart of study selection

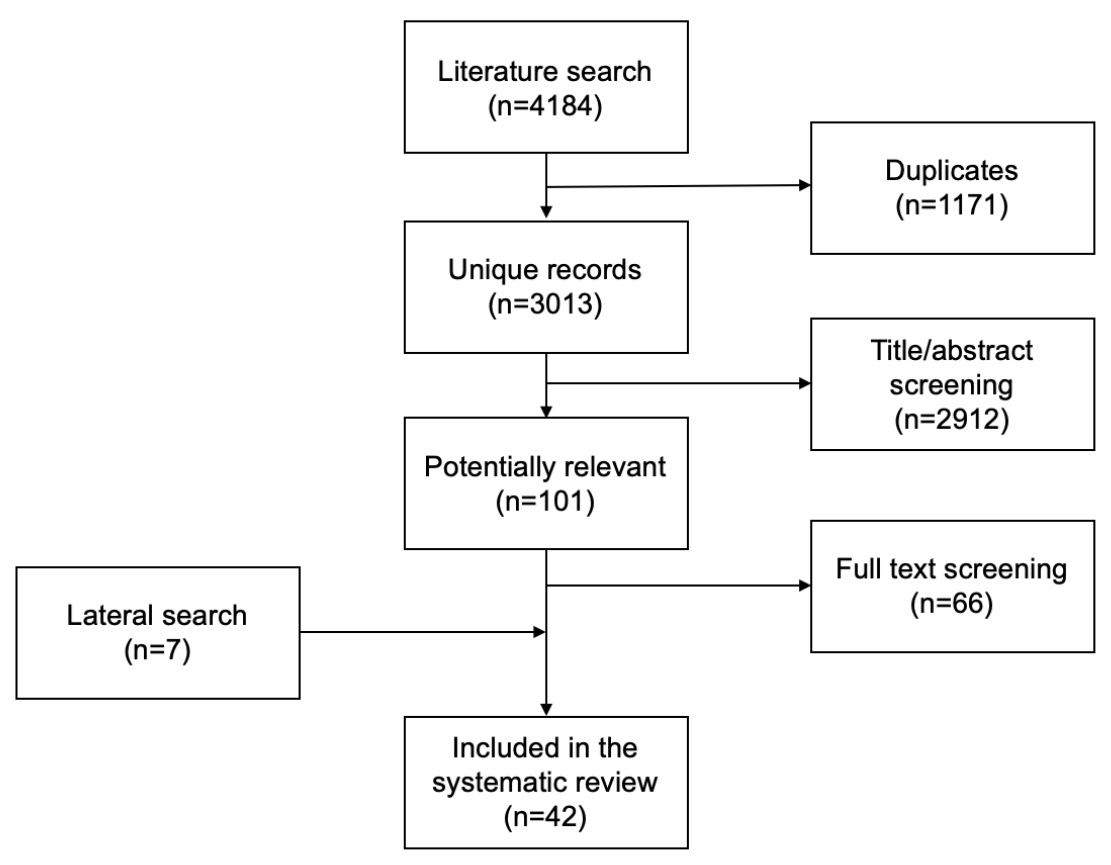

The number of studies included in the quantitative analyses varied by early-life factor and outcome considered. 
Figure 2. Assessed risk factors across the included studies

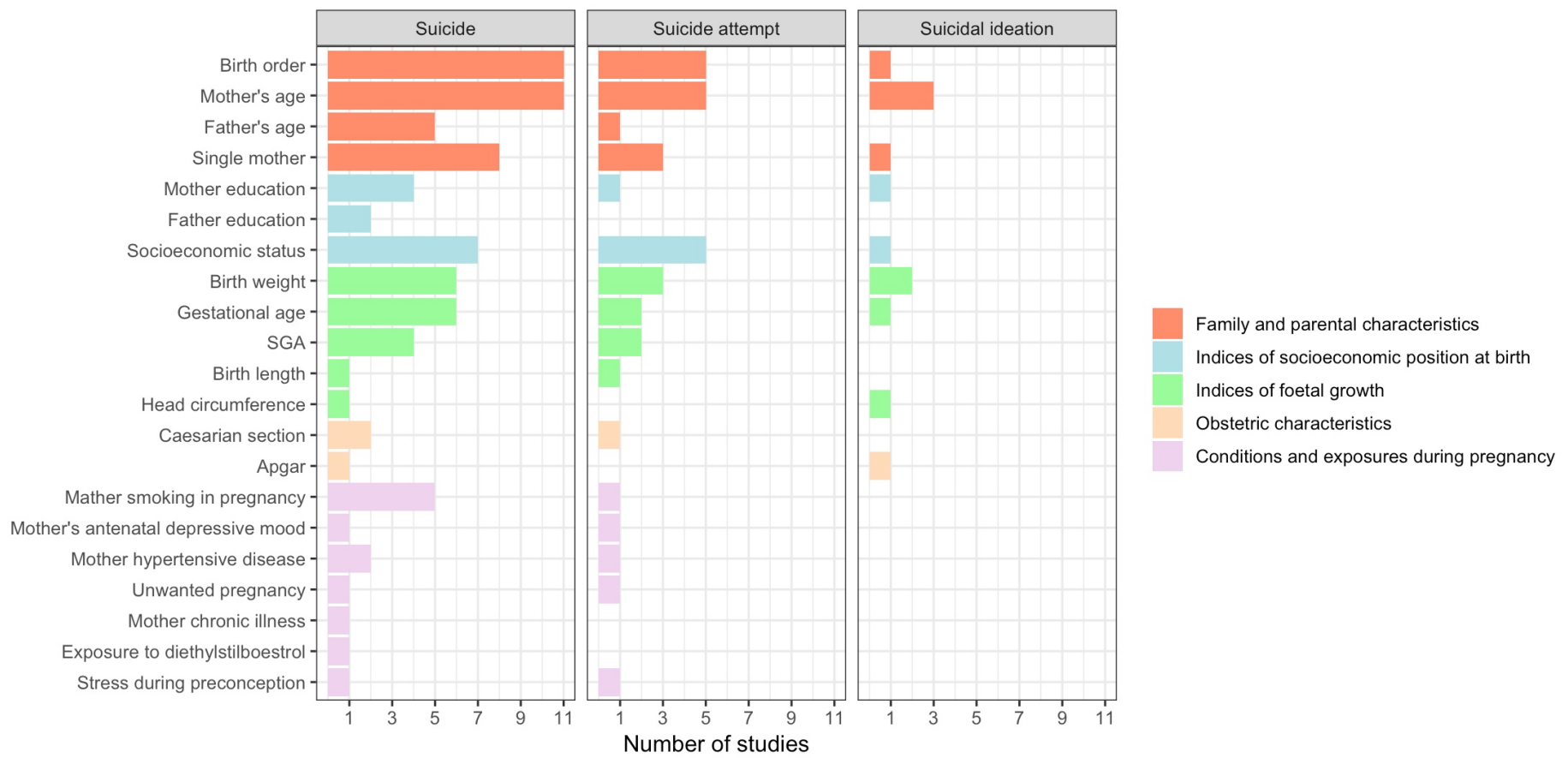

The figure reports the number of studies in which each individual risk factor was analysed, and includes multiple studies published using the same data. 
Figure 3. Pooled Odds Ratios for the association between in-utero and perinatal risk factors and suicide
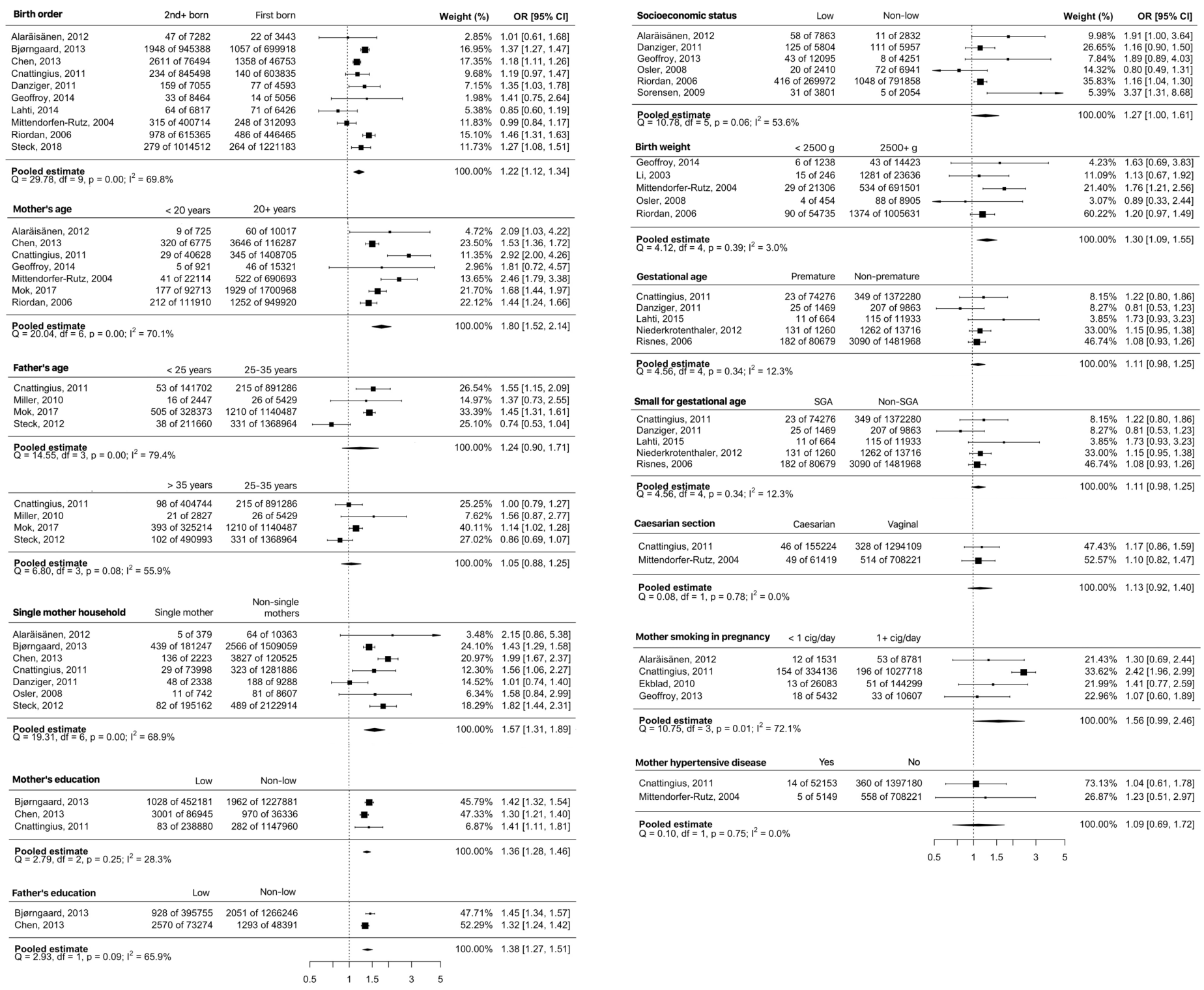

The figure shows the forest plot reporting the association between in-utero and perinatal risk factors and suicide for each single study entered in the analysis and the pooled random-effect estimate. Study published using the same data are considered only once. 
Figure 4. Pooled Odds Ratios for the association between in-utero and perinatal risk factors and suicide attempt and suicidal ideation
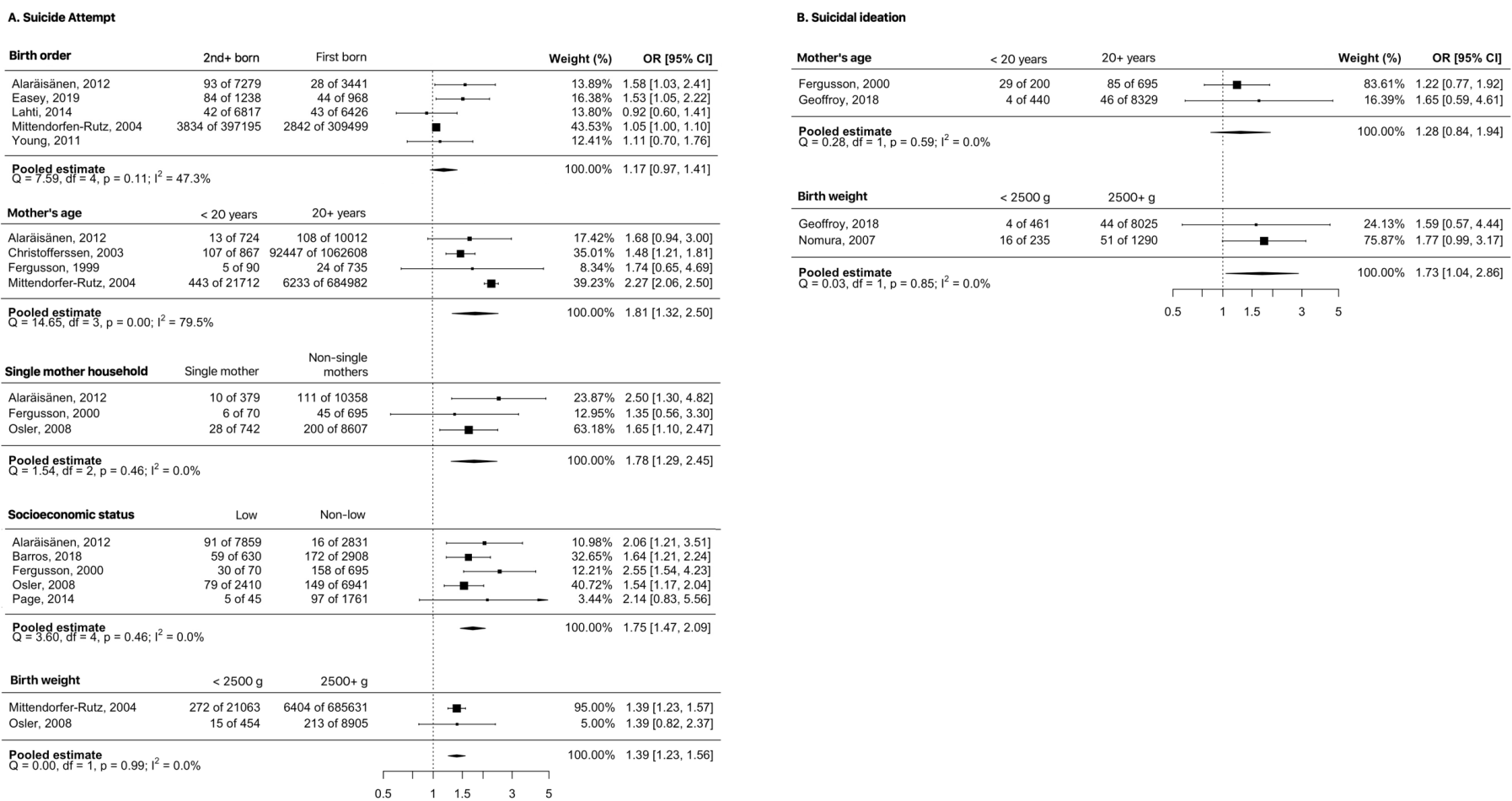

The figure shows the forest plot reporting the association between in-utero and perinatal risk factors and suicide attempt and suicidal ideation for each single study entered in the analysis and the pooled random-effect estimate. Study published using the same data are considered only once. 
Figure 5. Subgroup analysis by age at follow-up

\begin{tabular}{|c|c|c|c|c|}
\hline Exposure & Subgroup & N. studies & & OR $[95 \% \mathrm{Cl}]$ \\
\hline \multicolumn{5}{|l|}{ Suicide } \\
\hline Birth order $2+v s 1$ & $\begin{array}{l}\text { adult } \\
\text { youth }\end{array}$ & $\begin{array}{l}6 \\
4\end{array}$ & -1 & $\begin{array}{l}1.31 \\
1.16\end{array}[1.16,1.486,1.27]$ \\
\hline Birth order $2-3$ vs 1 & $\begin{array}{l}\text { adult } \\
\text { youth }\end{array}$ & $\begin{array}{l}5 \\
2\end{array}$ & $=-1$ & $\begin{array}{l}1.18[1.00,1.39] \\
1.07[0.91,1.26]\end{array}$ \\
\hline Birth order 4+ vs 1 & $\begin{array}{l}\text { adult } \\
\text { youth }\end{array}$ & $\begin{array}{l}5 \\
2\end{array}$ & 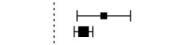 & $\begin{array}{l}1.64[1.26,2.14] \\
1.34[1.22,1.47]\end{array}$ \\
\hline Mather's young age & $\begin{array}{l}\text { adult } \\
\text { youth }\end{array}$ & $\begin{array}{l}4 \\
3\end{array}$ & $\rightleftarrows$ & $\begin{array}{l}1.56[1.41,1.73] \\
2.16[1.40,3.34]\end{array}$ \\
\hline Father's young age & $\begin{array}{l}\text { adult } \\
\text { youth }\end{array}$ & $\frac{2}{2}$ & $=$ & $\begin{array}{l}1.45[1.31,1.60] \\
1.08[0.53,2.22]\end{array}$ \\
\hline Father's advanced age & $=\begin{array}{l}\text { adult } \\
\text { youth }\end{array}$ & $\frac{2}{2}$ & $H=-1$ & $\begin{array}{l}1.16[0.99,1.36] \\
0.92[0.78,1.09]\end{array}$ \\
\hline Single mother & $\begin{array}{l}\text { adult } \\
\text { youth }\end{array}$ & $\begin{array}{l}4 \\
3\end{array}$ & -1 & $\begin{array}{l}1.34[1.07,1.68] \\
1.88[1.64,2.15]\end{array}$ \\
\hline Mother's low education & $n \begin{array}{l}\text { adult } \\
\text { youth }\end{array}$ & $\frac{1}{2}$ & $=$ & $\begin{array}{l}1.42[11.31,1.54] \\
1.31[1.22,1.41]\end{array}$ \\
\hline Father's low education & $\begin{array}{l}\text { adult } \\
\text { youth }\end{array}$ & 1 & $=$ & $\begin{array}{l}1.45 \\
1.32[1.34,1.53,1.42]\end{array}$ \\
\hline Low birthweight & $\begin{array}{l}\text { adult } \\
\text { youth }\end{array}$ & $\begin{array}{l}3 \\
1\end{array}$ & $\because$ & $\begin{array}{l}1.21[0.99,1.48] \\
1.47[0.96,2.25]\end{array}$ \\
\hline Gestational age & $\begin{array}{l}\text { adult } \\
\text { youth }\end{array}$ & ${ }_{1}^{4}$ & $\because$ & $\begin{array}{l}1.10[0.95,1.28] \\
1.22[0.80,1.86]\end{array}$ \\
\hline SGA & $\begin{array}{l}\text { adult } \\
\text { youth }\end{array}$ & $\begin{array}{l}3 \\
1\end{array}$ & $=-1$ & $\begin{array}{l}1.19[1.00,1.41] \\
1.16[0.67,2.01]\end{array}$ \\
\hline Smoking in pregnancy & $\begin{array}{c}\text { adult } \\
\text { youth }\end{array}$ & $\frac{2}{2}$ & $\longmapsto$ & $\begin{array}{l}1.17[0.77,1.78] \\
2.00[1.21,3.31]\end{array}$ \\
\hline \multicolumn{5}{|l|}{ Suicide attempt } \\
\hline Birth order $2+v s$ & $\begin{array}{l}\text { adult } \\
\text { youth }\end{array}$ & $\frac{2}{3}$ & $\because-$ & $\begin{array}{l}1.21[0.72,2.04] \\
1.15[0.92,1.44]\end{array}$ \\
\hline Mather's young age & $\begin{array}{l}\text { adult } \\
\text { youth }\end{array}$ & $\begin{array}{l}1 \\
3\end{array}$ & $\longmapsto$ & $\begin{array}{l}1.68[0.94,3.00] \\
1.84[1.26,2.68]\end{array}$ \\
\hline Single mother & $\begin{array}{l}\text { adult } \\
\text { youth }\end{array}$ & ${ }_{1}^{2}$ & $\longmapsto$ & $\begin{array}{l}1.87[1.29,2.72] \\
1.35[0.55,3.30]\end{array}$ \\
\hline Low SES & $\begin{array}{l}\text { adult } \\
\text { youth }\end{array}$ & $\frac{2}{3}$ & $\mapsto$ & $\begin{array}{l}1.64[1.28,2.10] \\
1.90[1.44,2.51]\end{array}$ \\
\hline Low birthweight & $\begin{array}{l}\text { adult } \\
\text { youth }\end{array}$ & $\begin{array}{l}1 \\
1\end{array}$ & $\dot{E}$ & $\begin{array}{l}1.39[0.82,2.37] \\
1.39[1.23,1.57]\end{array}$ \\
\hline \multicolumn{5}{|l|}{ Suicidal ideation } \\
\hline Mather's young age & $\begin{array}{l}\text { adult } \\
\text { youth }\end{array}$ & 1 & $\stackrel{\bullet}{\bullet}$ & $\begin{array}{l}1.65[0.59,4.61] \\
1.22[0.78,1.92]\end{array}$ \\
\hline & & 0 & $\begin{array}{ll}1 & 1.5 \\
1.5\end{array}$ & \\
\hline
\end{tabular}

The figure shows the pooled estimates for each comparison, stratified by age at follow-up. 


\section{Supplementary appendix}

Developmental origins of suicide: systematic review and meta-analysis of the in-utero and perinatal influences on suicide risk

Massimiliano Orri, David Gunnell, Stephane Richard-Devantoy, Despina Bolanis, Jill Boruff, Gustavo Turecki \& Marie-Claude Geoffroy 


\section{Methods}

\section{Literature search}

A health sciences librarian (JB) conducted searches in MEDLINE, EMBASE and PsycInfo, from database inception to May 3, 2018 using the combination of keywords and subject headings presented in supplementary table 1 . The search strategy was developed for MEDLINE and modified for the other databases using the observational studies methodological filter from the Scottish Intercollegiate Guideline Network. ${ }^{1}$ The search strategy was peer reviewed by another health sciences librarian $(\mathrm{CN})$ using the Peer Review of Electronic Search Strategies checklist. ${ }^{2}$ Additionally, we searched the reference lists of all identified studies and hand searched key journals (ie, JAMA, JAMA Psychiatry, The Lancet, The Lancet Psychiatry, BMJ, International Journal of Epidemiology, The American Journal of Psychiatry, British Journal of Psychiatry, Psychological Medicine, Acta Psychiatrica Scandinavica, American Journal of Public Health, Social Psychiatry and Psychiatric Epidemiology). Search results were exported into EndNote and all duplicates were removed. A PRISMA flow chart was used to track the number of studies in each stage of the review (see figure 1 in manuscript). Citations were imported into the web software Rayyan, ${ }^{3}$ which facilitated independent and blind screening of the studies by two researchers (MO and DB), and subsequent comparisons.

\section{Harmonisation of in-utero and perinatal factors}

Supplementary tables 2 to 13 show categorisation of in-utero and perinatal exposure factors assessed in the studies included in the meta-analysis and how they were harmonised across studies. Data were harmonised in order to maximize the number of studies included in the meta-analysis with homogeneous assessment of the exposure.

Birth order was categorized as $1^{\text {st }}$ versus $2^{\text {nd }}$ or later born (supplementary table 2) and dose-response association was examined using birth order categorised as $1^{\text {st }}$ versus $2^{\text {nd }}$ and $3^{\text {rd }}$ born versus $4^{\text {th }}$ or later born for a subgroup of studies $(n=6)$ (supplementary table 3).

Mother's age at child birth was categorised as younger age, ie, $<20$ years, versus older age, ie, $\geq 20$ years ( $\mathrm{n}=8$ ), except for 1 study in which maternal age was categorised as $<18$ years versus $\geq 18$ years (supplementary table 4). Father's age at child birth was categorised as follows: younger age, ie, $<25$ years, versus average age, ie, 25-35 years, versus older age, ie, $\geq 35$ years (supplementary table 3 ).

Household composition was categorised as single-parent family versus non-single-parent family (supplementary table 4). Single-parent family mainly included single mothers (ie, not living with the biological father of the child at child birth), separated or divorced at child birth, and widowed at child birth. While most studies assessed mother's status, 2 studies did not specify whether the single parent was the mother or the father.

Mother's and father's levels of education at child birth were categorised into lower (ie, primary/lower education or lack of formal education, or $<10$ years of education) versus higher (supplementary tables 7 and 8).

Socioeconomic status was categorised as lower versus higher (supplementary table 9). However, as detailed in supplementary table 9 included studies relied on heterogeneous indicators of low socioeconomic status, eg, father's unskilled or manual work, low level of socioeconomic status according to Elley \& Irving (1976) scale of socioeconomic status, professional occupation according to UK classification (Class I to VI).

Birthweight was categorised as low, ie, $<2500$ grams, versus normal, ie, 2500 grams (supplemental table 10).

Gestational age at birth was categorised as low, ie, $<37$ or 38 weeks, versus normal, ie, $\geq 37$ or 38 weeks (supplemental table 11). Small for gestational age (ie, gestational age adjusted for birthweight) was categorised as small, ie, lower tertiles of the distribution or -2 SD from the distribution mean, versus normal (supplementary table 12).

Mother smoking during pregnancy was categorised as smoker, defined as mother smoking $>1$ cigarette per day during pregnancy versus no smoker (supplementary table 13).

\section{Analysis of the between-study heterogeneity}

Meta-analysis was performed using the DerSimonian and Laird inverse-variance-weighted random-effect models. ${ }^{4}$ The heterogeneity across studies was investigated using the (1) Cochrane Q statistic and (2) $I^{2}$ statistic (supplementary table 14). (1) Cochran's Q statistic tests whether variability in observed effect sizes is larger than expected based on sampling variability alone (significant test suggesting heterogeneity). (2) $\mathrm{I}^{2}$ statistic represents the percentage of variation across studies that is due to heterogeneity rather than chance and was computed as follows: $\mathrm{I}^{2}=100 \% \mathrm{x}(\mathrm{Q}-\mathrm{df}) / \mathrm{Q}$. Supplementary table 14 also reports results of the meta-regression analyses investigating the influence of age at follow-up ( $\leq 30$ years versus $>30$ years) as moderator, tested using the $\mathrm{Q}$ statistics, the proportion of heterogeneity explained by the moderator in the meta-regression model $\left(\mathrm{R}^{2}\right)$, and the proportion of residual heterogeneity $\left(\mathrm{I}^{2}\right)$ after considering the effect of the moderator.

\section{Risk of publication bias analysis}

Supplemental table 15 and the funnel plots in supplementary figures 1 and 2 show report risk of publication bias results. The asymmetry of the funnel plots was tested using the Egger's regression test for random-effect models. When publication bias was suggested by a significant Egger's test, we used the Trim and Fill method to further explore the extent of the possible bias. The Trim and Fill is a nonparametric (rank-based) data augmentation technique method; it first estimates the number of studies missing from a meta-analysis due to suppression of the most extreme results on one side of the funnel plot, then augments the observed data so that the funnel plot is more symmetric, and finally recalculates the summary estimate based on the complete data. This analysis indicated possible publication bias for mother smoking during pregnancy ( $p=0.002$ for the Egger test) and maternal age at child birth ( $p=0.034$ for the Egger test). For mother smoking during pregnancy, explorations using the Trim and Fill method suggested that two studies were potentially missing due to publication bias. Including those studies would make the 
comparison between mother smoking during pregnancy versus non-smoking statistically significant - whereas mother smoking during pregnancy was not associated with suicide mortality in main analysis (figure 3 in the manuscript). The funnel plot for mother smoking during pregnancy in figure 1 represents the estimated effect size (log OR, $\mathrm{x}$-axis) and corresponding standard error (y-axis) of the analysed studies (indicated by black dots) and of the potentially missing studies according to the Trim and Fill analysis (indicated by white dots). It is important to note that (1) our review suggested that this association is likely to be confounded by other concurrent factors, and (2) the comparison is strongly influenced by one study (Cnattingius et al. 2011) that, if removed, would render the pooled OR for the three remaining studies non-significant (see sensitivity analyses). For maternal age at child birth, explorations using the Trim and Fill method suggested that three studies were potentially missing due to publication bias. However, differently from maternal smoking, including those study would not change the result of the metaanalysis.

\section{Sensitivity analyses}

We conducted a first sensitivity analyses (supplemental table 16) to establish how strong a confounding factor should be in order to explain away (ie, render not statistically significant) the association of each significant in-utero and perinatal factor on outcome. Our analyses were based on E-value, defined as the minimum strength of association, on the risk ratio (RR) scale, that an unmeasured confounder would need to have with both the treatment and the outcome to fully explain away a specific treatmentoutcome association. ${ }^{5}$ To illustrate, mother's younger age and suicide association (pooled OR 1.80, CI 1.52-2.14) would be explained away by adjusting for a confounding factor associated with both mother's age and suicide with a RR of 3.00. Potential confounding factors for mother's age are those listed in supplementary table 16 and individually analysed in our study. Of those risk factors, none were associated with suicide with an OR of 3.00 (OR can be considered a good approximation of RR due to the low frequency of outcome). This suggests that association between mother's young age and suicide is robust to adjustment for all other in-utero and perinatal factors considered in this meta-analysis. By definition, confounding factors are measured before or at the same time of an exposure (ie, not between the exposure and the outcome, see collider bias). ${ }^{6}$ Therefore, factors such as depression in adolescence, stressor(s) in adulthood, adverse childhood experiences (potentially associated with suicide with large ORs) cannot be considered as potential confounding factors here. Similar observations apply to other exposures investigated in our meta-analysis, suggesting the robustness of our results to adjustment of in-utero and perinatal factors included in this metaanalysis.

We conduct a second sensitivity analysis (supplemental figures 3 and 4) to establish the contribution of each single study to the pooled estimate and the between-study heterogeneity. In this analysis, we re-estimated the pooled OR removing one study at the time. The supplemental figures 3 and 4 show ORs and CI for each comparison by in-utero and perinatal factor. The removed study is indicated in the $\mathrm{x}$-axis. Heterogeneity $\left(\mathrm{I}^{2}\right)$ is indicated by the colour's gradient. The result of this sensitivity analysis shows that the pooled estimates are overall robust to the influence of each single study. In particular, for the studies having high residual heterogeneity $\left(\mathrm{I}^{2}>50 \%\right)$ after the meta-regression analysis (ie, birth order $2^{\text {nd }}-3^{\text {rd }}$ vs $1^{\text {st }}$ born for suicide and mother's age for suicide and suicide attempt), the following was found:

For birth order $2^{\text {nd }}-3^{\text {rd }}$ vs $1^{\text {st }}$, the study explaining the most heterogeneity was Mittenforfer-Rutz, 2004. The residual heterogeneity after removing this study was $54.7 \%$, with no modification of the pooled OR $(1.22,1.12-1.34)$.

For mother's age, the studies explaining the most heterogeneity was Cnattingus, 2011 . The residual heterogeneity after removing this study was $52.7 \%$, with no modification of the pooled OR $(1.66,1.47-1.89)$.

For mother's age in the association with suicide attempt, the studies explaining the most heterogeneity were Mittenforfer-Rutz, 2004, and Christofferssen, 2003. The residual heterogeneity after removing either studies was $0 \%$, with no modification of the pooled OR (e.g., 1.51, 1.25-1.82 after removing Mittenforfer-Rutz 2004).

\section{Results}

\section{Associations between in-utero and perinatal influences and suicide among studies controlling for parental psychopathology}

Supplementary tables 17 and 18 summarise findings from studies that adjusted for parental psychopathology, including mental disorders, suicidal behaviours, substance and alcohol abuse. For each risk factor we reported the crude association (or minimally adjusted association) and the fully adjusted association including parental psychopathology in bold (the full list of adjustment variable is provided). Two methods of adjustment were used across identified studies: multiple regression and/or sibling design (ie, calculating association within families, or using fixed-effect models). Overall, adjusting for parental psychopathology did not substantially reduce the estimates, with only one exception (see Class, 2014). ${ }^{7}$ 


\section{Supplementary Table 1. Literature search strategy}

\section{Ovid Medline search}

1. Suicidal Ideation/ or Suicide/ or Suicide, Attempted/ or self-injurious behavior/ or self mutilation/

2. (suicide* or suicidal* or self harm* or self mutilation).ti,ab,kf.

3. 1 or 2

4. Birth Order/

5. PARITY/

6. Family Characteristics/

7. SIBLINGS/

8. Birth Weight

9. exp Infant, Low Birth Weight/

10. maternal age/

11. Paternal Age/

12. exp Fetal Development/ or ASPHYXIA NEONATORUM/

13. exp Perinatal Care/

14. Prenatal Care/

15. Life Change Events/

16. Single Parent/ or Single Parent Family/

17. Smoking/

18. poverty/

19. exp Family Relations/

20. (((neonat* or perinatal or newborn) adj2 asphyxia) or in utero or developmental origin* or (early adj3 (life event? or life experienc*)) or adverse childhood experience* or childhood adversit* or (birth adj2 order) or parity or multiparity or (family adj2 size) or (sibship adj2 size) or (number adj2 siblings) or ((birth adj (weight or length)) or under weight or underweight or maternal age or (mother* adj2 age) or paternal age or (father* adj2 age) or (parent* adj2 age) or foetal growth or fetal growth or early life or perinatal or prenatal or maternal smoking or single parent*)).ti,ab,kf.

21. ((Socioeconomic or income or poverty) and (birth or maternal or paternal or family)).ti,ab,kf.

22. ((family or familial) adj2 (factor? or characteristics or environment* or advers* or relationship*)).ti,ab,kf.

23. or $/ 4-22$

24. 3 and 23

25. Epidemiologic studies/

26. exp case control studies/

27. exp cohort studies/

28. Case control.ti,ab,kf

29. (cohort adj (study or studies)).ti,ab,kf.

30. Cohort analy*.ti,ab,kf.

31. (Follow up adj (study or studies)).ti,ab,kf.

32. (observational adj (study or studies)).ti,ab,kf.

33. Longitudinal.ti,ab,kf.

34. Retrospective.ti,ab,kf.

35. Cross sectional.ti,ab,kf.

36. Cross-sectional studies/

37. "Incidence"/

38. Registries/

39. (registry or register).ti,ab,kf.

40.25 or 26 or 27 or 28 or 29 or 30 or 31 or 32 or 33 or 34 or 35 or 36 or 37 or 38 or 39

41.24 and 40 
Supplementary Table 2. Original assessment of birth order in included studies and how birth order was harmonised for the meta-analysis

\begin{tabular}{lll}
\hline Study & Original categorisation & Harmonised categorisation \\
\hline Suicide mortality and/or attempt & & $1,2+$ \\
\hline Alaräisänen 2012 & $1,2-5,6+$ & $1,2+$ \\
\hline Bjørngaard 2013 & $1,2,3,4+$ & $1,2+$ \\
\hline Cnattingius 2011 & $1,2+$ & $1,2+$ \\
\hline Mittendorfer-Rutz 2004 & $1,2-3,4+$ & $1,2+$ \\
\hline Geoffroy 2014 & $1,2,3,4+$ & $1,2+$ \\
\hline Lahti 2014 & $1,2,3,4+$ & $1,2+$ \\
\hline Riordan 2006 & $1,2,3,4+$ & $1,2+$ \\
\hline Chen 2013 & $1,2,3,4+$ & $1,2+$ \\
\hline Danziger 2011 & $1,2-3,4+$ & $1,2+(1=$ only child or first born $)$ \\
\hline Steck 2018 & Only child, First, Middle, Last & \\
\hline Suicide attempt & & $1,2+$ \\
\hline Young 2011 & $1,2+$ & $1,2+$ \\
\hline Easey 2019 & $1,2,3+$ & \\
\hline
\end{tabular}

Supplementary Table 3. Original assessment of birth order in included studies and how birth order was harmonised for the meta-analysis testing dose-response association

\begin{tabular}{lll}
\hline Study & Original categorisation & Harmonised categorisation \\
\hline Suicide mortality and/or attempt & & \\
\hline Bjørngaard 2013 & $1,2,3,4+$ & $1,2-3,4+$ \\
\hline Mittendorfer-Rutz 2004 & $1,2-3,4+$ & $1,2-3,4+$ \\
\hline Geoffroy 2014 & $1,2,3,4+$ & $1,2-3,4+$ \\
\hline Lahti 2014 & $1,2,3,4+$ & $1,2-3,4+$ \\
\hline Riordan 2006 & $1,2,3,4+$ & $1,2-3,4+$ \\
\hline Chen 2013 & $1,2,3,4+$ & $1,2-3,4+$ \\
\hline Danziger 2011 & $1,2-3,4+$ & $1,2-3,4+$ \\
\hline
\end{tabular}

Supplementary Table 4. Original assessment of mother's age in included studies and how mother's age was harmonised for the meta-analysis

\begin{tabular}{lll}
\hline Study & Original categorisation & Harmonised categorisation \\
\hline Suicide mortality and/or attempt & & \\
\hline Alaräisänen 2012 & $<20,20-34,35+$ & $<20, \geq 20$ \\
\hline Bjørngaard 2013 & $<20,20-24,25-29,30-34,35+$ & $<20$ \\
\hline Cnattingius 2011 & $<20,20-24,25-29,30-34,35+$ & $<20, \geq 20$ \\
\hline Mittendorfer-Rutz 2004 & $<20,20-29,30+$ & $<20, \geq 20$ \\
\hline Geoffroy 2014 & $<20,20-29,30+$ & $<20, \geq 20$ \\
\hline Riordan 2006 & $<20,20-24,25-29,30-34,35+$ & $<20, \geq 20$ \\
\hline Chen 2013 & $<20,20-24,25-29,30-34,35+$ & $<20, \geq 20$ \\
\hline Mok 2017 & $<20,20-24,25-29,30-34,35-39,40-45,45+$ & \\
\hline & & $<20, \geq 20$ \\
\hline Suicide attempt & $<20, \geq 20$ \\
\hline Young 2011 & $<20,20-24,25-29,30-34,35+$ & $<20, \geq 20$ \\
\hline Fergusson 1999 & $<20,20-24,25-29,30+$ & \\
\hline Christofferssen 2003 & $<20, \geq 20$ & $<20, \geq 20$ \\
\hline & & \\
\hline Suicidal ideation & $<20,20-29,30+$ & \\
\hline Geoffroy 2018 & \\
\hline
\end{tabular}

Supplementary Table 5. Original assessment of father's age in included studies and how father's age was harmonised for the meta-analysis

\begin{tabular}{lll}
\hline Study & Original categorisation & Harmonised categorisation \\
\hline Suicide mortality and/or attempt & & \\
\hline Miller 2010 & $<25,25-29,30-34,35-39,40-45,45+$ & $<25,25-35, \geq 35$ \\
\hline Cnattingius 2011 & $<20,20-24,25-29,30-34,35+$ & $<25,25-35, \geq 35$ \\
\hline Mok 2017 & $<20,20-24,25-29,30-34,35-39,40-45,45+$ & $<25,25-35, \geq 35$ \\
\hline Steck 2018 & $<25,25-34,35-44,45+$ & $<25,25-35, \geq 35$ \\
\hline
\end{tabular}


Supplementary Table 6. Original assessment of household composition in included studies and how household composition was harmonised for the meta-analysis

\begin{tabular}{cll}
\hline Study & Original categorisation & Harmonised categorisation \\
\hline Suicide mortality and/or attempt & Two-parent family, single-parent family & Single-parent family, not single-parent family (ie, two-parent family) \\
\hline Alaräisänen 2012 & Mother married or cohabitant, other & $\begin{array}{l}\text { Single-parent family (ie, other), not single-parent family (ie, married } \\
\text { or cohabitant) }\end{array}$ \\
\hline Bjørngaard 2013 & $\begin{array}{l}\text { Mother living with infant father, not living } \\
\text { with infant father }\end{array}$ & $\begin{array}{l}\text { Single-parent family (ie, not living with infant father), not single- } \\
\text { parent family (ie, living with infant father) }\end{array}$ \\
\hline Cnattingius 2011 & $\begin{array}{l}\text { Mother married, not-married } \\
\text { (single/divorced/widowed) }\end{array}$ & $\begin{array}{l}\text { Single-parent family (ie, not-married), not single-parent family (ie, } \\
\text { single/divorced/widowed) }\end{array}$ \\
\hline Chen 2013 & Mother married, other & $\begin{array}{l}\text { Single-parent family (ie, other), not single-parent family (ie, mother } \\
\text { married) }\end{array}$ \\
\hline Danziger 2011 & $\begin{array}{l}\text { Mother married, not-married } \\
\text { (single/divorced/widowed) }\end{array}$ & $\begin{array}{l}\text { Single-parent family (ie, not-married), not single-parent family (ie, } \\
\text { single/divorced/widowed) }\end{array}$ \\
\hline Osler 2007 & $\begin{array}{l}\text { Couple with children, single parent with } \\
\text { children, institution }\end{array}$ & $\begin{array}{l}\text { Single-parent family (ie, single parent with children), not single- } \\
\text { parent family (ie, couple with children); institution was excluded }\end{array}$ \\
\hline Steck 2018* & & \\
\hline Suicide attempt & Single parent family, not single parent family & Single-parent family, not single-parent family \\
\hline Fergusson $2000 *$ & & \\
\hline
\end{tabular}

* Did not specified status of the mother

Supplementary Table 7. Original assessment of mother's education in included studies and how mother's education was harmonised for the meta-analysis

\begin{tabular}{cll}
\hline Study & Original categorisation & Harmonised categorisation \\
\hline Suicide mortality and/or attempt & & \\
\hline Bjørngaard 2013 & $\begin{array}{l}\text { Primary/lower secondary, upper secondary, } \\
\text { college/university }\end{array}$ & $\begin{array}{l}\text { Lower (ie, primary/lower education), higher (ie, upper secondary, } \\
\text { college/university) }\end{array}$ \\
\hline Cnattingius 2011 & Years of education: $<10,10-12,13-14, \geq 14$ & Lower (ie, $<10$ years), higher (ie, $\geq 10$ years) \\
\hline Chen 2013 & Years of education: $<7,7-9,10-12, \geq 13$ & Lower (ie, $<10$ years), higher (ie, $\geq 10$ years) \\
\hline Suicide attempt & & \\
\hline Fergusson 2000 & $\begin{array}{l}\text { Lack formal education, at least formal } \\
\text { education }\end{array}$ & $\begin{array}{l}\text { Lower (ie, lack formal education), higher (ie, at least formal } \\
\text { education) }\end{array}$ \\
\hline
\end{tabular}

Supplementary Table 8. Original assessment of father's education in included studies and how father's education was harmonised for the meta-analysis

\begin{tabular}{lll}
\hline Study & Original categorisation & Harmonised categorisation \\
\hline Suicide mortality and/or attempt & & \\
\hline Bjørngaard 2013 & $\begin{array}{l}\text { Primary/lower secondary, upper secondary, } \\
\text { college/university }\end{array}$ & $\begin{array}{l}\text { Lower (ie, primary/lower education), higher (ie, upper secondary, } \\
\text { college/university) }\end{array}$ \\
\hline Chen 2013 & Years of education: $<7,7-9,10-12, \geq 13$ & Lower (ie, $<10$ years), higher (ie, $\geq 10$ years) \\
\hline
\end{tabular}


Supplementary Table 9. Original assessment of socioeconomic status in included studies and how socioeconomic status was harmonised for the meta-analysis

\begin{tabular}{|c|c|c|}
\hline Study & Original categorisation & Harmonised categorisation \\
\hline \multicolumn{3}{|c|}{ Suicide mortality and/or attempt } \\
\hline Alaräisänen $2012^{\text {a }}$ & $\begin{array}{l}\text { Class I and II (high), Class III and IV (low), } \\
\text { Class V (farmers) }\end{array}$ & Low (ie, Class I and II, and Class V), high (ie, Class III and IV) \\
\hline Geoffroy $2014^{b}$ & Non-manual, Manual & Low (ie, manual), high (ie, non-manual) \\
\hline Riordan $2006^{\mathrm{c}}$ & Professional, Skilled, Unskilled & Low (ie, unskilled), high (ie, professional, skilled) \\
\hline Osler $2007^{\mathrm{d}}$ & $\begin{array}{l}\text { Employee, civil servant, Self-employed, } \\
\text { Skilled worker, Unskilled worker, } \\
\text { Outside/Unknown }\end{array}$ & $\begin{array}{l}\text { Low (ie, Unskilled worker), high (ie, Employee, civil servant \& Self- } \\
\text { employed \& Skilled worker \& Self-employed \& Outside/Unknown) }\end{array}$ \\
\hline Danziger $2011^{\mathrm{e}}$ & $\begin{array}{l}\text { Non-manual, Self-employed of farmer, } \\
\text { Manual, Other }\end{array}$ & $\begin{array}{l}\text { Low (ie, Manual), high (ie, Non-manual \& Self-employed of farmer } \\
\text { \& Other) }\end{array}$ \\
\hline Sorensen $2009^{f}$ & $\begin{array}{l}\text { Parent social status High, Parent social status } \\
\text { Low }\end{array}$ & $\begin{array}{l}\text { Low (ie, Parent social status Low), high (ie, Parent social status } \\
\text { High) }\end{array}$ \\
\hline \multicolumn{3}{|l|}{ Suicide attempt } \\
\hline Barros $2018^{\mathrm{g}}$ & Quintiles & Low (lower quintile), high (second to fifth quantile) \\
\hline Fergusson $2000^{\mathrm{h}}$ & $\begin{array}{l}\text { Professional/Managerial, } \\
\text { Clerical/Technical/Skilled, Semi- } \\
\text { skilled/Unskilled }\end{array}$ & $\begin{array}{l}\text { Low (ie, Semi-skilled/Unskilled), high (ie, Professional/Managerial } \\
\text { \& Clerical/Technical/Skilled) }\end{array}$ \\
\hline Page $2014^{\mathrm{i}}$ & Class I and II, Class III and IV, Class V and VI & Low (ie, Class IV and V), high (ie, Class I, II, and III) \\
\hline
\end{tabular}

a. Based on father's occupation (reported by who the mother), assessed in 1966. When the father's occupational status was not known the mother's information on her occupational status was used instead.

b. Based on father's occupation from mother's report of their husband's occupation soon after child's birth (or if missing at 7 years). Occupations were categorized according to the 1951Registrar General's Classification into two categories: non-manual (I/II/IIINM) and manual (IIIM/IV/V).

c. Based on parental occupation

d. Father's occupation at birth of a participant was recorded in 23 strata: non-urban self-employed (four strata) urban self-employed

(six strata); employee and civil servants (five strata), skilled and unskilled workers (five strata); pensioners; students and unknown. Preliminary data analyses

showed that the strata could be combined, leaving five categories

e. Not further specified

f. The social status classification was based on information about the breadwinner's occupation, breadwinner's education, type of income, and quality of house

g. Derived from principal component analysis of the variables: delivery payment mode, mother's schooling, height, and skin colour

h. Family socio-economic status at the time of the child's birth. This was assessed using the Elley \& Irving (1976) scale of socio-economic status for New Zealand.

This scale categorizes families into six classes on the basis of paternal occupation. For this analysis, the scale was collapsed into three levels as follows: 1) Levels

1, 2 (professional, managerial); 2) Levels 3, 4 (clerical, technical, skilled); and 3) Levels 5, 6 (semi-skilled, unskilled, unemployed).

i. Professional occupations (class I), managerial and technical occupations (class II), skilled non-manual occupations (class III-NM), skilled manual occupations

(class IIIM), partly skilled occupations (class IV), and unskilled occupations (class V). The highest social class of either parent was used to define parental social class.

Supplementary Table 10. Original assessment of birthweight in included studies and how birthweight was harmonised for the meta-analysis

\begin{tabular}{lll}
\hline Study & Original categorisation (in grams) & Harmonised categorisation (in grams) \\
\hline Suicide mortality and/or attempt & & \\
\hline Mittendorfer-Rutz 2004 & $<2500,2500-3250,3250-3750,3750-4450$, & $<2500, \geq 2500$ \\
& $>4500$ & \\
\hline Geoffroy 2014 & $<2500, \geq 2500$ & $<2500, \geq 2500$ \\
\hline Li 2003 & $<2500, \geq 2500$ & $<2500, \geq 2500$ \\
\hline Riordan 2006 & $<2500,2500-3250,3250-3750,3750-4450$, & $<2500, \geq 2500$ \\
\hline Osler 2008 & $>4500$ & $<2500, \geq 2500$ \\
\hline & $<2500,2500-3400,>3400$ & \\
\hline Suicide ideation & & $<2500, \geq 2500$ \\
\hline Geoffroy 2018 & $<2500, \geq 2500$ & $<2500, \geq 2500$ \\
\hline Nomura 2007 & $<2500, \geq 2500$ & \\
\hline
\end{tabular}

Supplementary Table 11. Original assessment of gestational age in included studies and how gestational age was harmonised for the meta-analysis

\begin{tabular}{lll}
\hline Study & Original categorisation (in grams) & Harmonised categorisation (in grams) \\
\hline Suicide mortality and/or attempt & & \\
\hline Risnes 2016 & $\begin{array}{l}\text { Weeks of gestation: } 22-33+6 \text { days, 34-36+6 } \\
\text { days, 37-41+6 days, } \geq 42\end{array}$ & Low (ie, $<37$ weeks), normal (ie, $\geq 37$ weeks) \\
\hline Cnattingius 2011 & Weeks of gestation: $<37, \geq 37$ & Low (ie, $<37$ weeks), normal (ie, $\geq 37$ weeks) \\
\hline Danziger 2011 & Weeks of gestation: $<38,28-41, \geq 42$ & Low (ie, $<38$ weeks), normal (ie, $\geq 38$ weeks) \\
\hline D’Onofrio 2013 & Weeks of gestation: $<37, \geq 37$ & Low (ie, $<37$ weeks), normal (ie, $\geq 37$ weeks) \\
\hline Niederkrotenthaler 2012 & Weeks of gestation: $<34,34-37,38-40, \geq 41$ & Low (ie, $<37$ weeks), normal (ie, $\geq 37$ weeks) \\
\hline
\end{tabular}


Supplementary Table 12. Original assessment of Small for Gestational Age in included studies and how Small for Gestational Age was harmonised for the meta-analysis

\begin{tabular}{cll}
\hline Study & Original categorisation (in grams) & Harmonised categorisation (in grams) \\
\hline Suicide mortality and/or attempt & & \\
\hline Cnattingius 2011 & $<-2 \mathrm{SD},-2$ to $-1,-1$ to $+1,+1$ to $+2,>+2$ & $\begin{array}{l}\text { Small for gestational age (ie, }<-2 \mathrm{SD}), \text { non-small for gestational age } \\
\text { (ie, } \geq-2 \mathrm{SD})\end{array}$ \\
\hline Niederkrotenthaler 2012 & $\begin{array}{l}\text { low weight short length, low weight, short } \\
\text { length, non-SGA }(>-2 \mathrm{SD})\end{array}$ & $\begin{array}{l}\text { Small for gestational age (ie, long, short, both), non-small for } \\
\text { gestational age (ie, } \geq-2 \mathrm{SD})\end{array}$ \\
\hline Lahti 2015 & $<-2 \mathrm{SD},-2$ to $+2,<+2 \mathrm{SD}$ & $\begin{array}{l}\text { Small for gestational age (ie, }<-2 \mathrm{SD}), \text { non-small for gestational age } \\
\text { (ie, } \geq-2 \mathrm{SD})\end{array}$ \\
\hline Danziger 2011 & Lowest tertile, Middle tertile, Higher tertile & $\begin{array}{l}\text { Small for gestational age (ie, lowest tertile), non-small for gestational } \\
\text { age middle tertile, higher tertile) }\end{array}$ \\
\hline
\end{tabular}

Supplementary Table 13. Original assessment of mother's smoking during pregnancy in included studies and how mother's smoking during pregnancy was harmonised for the meta-analysis

\begin{tabular}{lll}
\hline Study & Original categorisation (in grams) & Harmonised categorisation (in grams) \\
\hline Suicide mortality and/or attempt & & \\
\hline Alaräisänen 2012 & $>1$ cigarette/day, no & Yes (ie, $>1$ cigarette/day), no \\
\hline Cnattingius 2011 & $>9$ cigarettes/day, 1-9 cigarettes/day, no & Yes (ie, $>1$ cigarette/day), no \\
\hline Geoffroy 2014 & $>1$ cigarette/day, no & Yes (ie, $>1$ cigarette/day), no \\
\hline Ekblad 2010 & $>9$ cigarettes/day, 1-9 cigarettes/day, no & Yes (ie, $>1$ cigarette/day), no \\
\hline
\end{tabular}


Supplementary Table 14. Meta-regression analyses

\begin{tabular}{|c|c|c|c|c|c|c|c|c|c|}
\hline \multirow[t]{3}{*}{ Risk factor } & \multicolumn{3}{|c|}{ Heterogeneity - initial model } & \multicolumn{6}{|c|}{ Meta-regression: moderation analysis for age at follow-up ( $<30 \mathrm{vs}>30$ years) } \\
\hline & \multirow[t]{2}{*}{$\mathrm{Q}_{\mathrm{H}}(\mathrm{df})$} & \multirow[t]{2}{*}{$p$} & \multirow[t]{2}{*}{$\mathrm{I}^{2}(\%)$} & \multicolumn{2}{|c|}{ Test for moderation } & \multicolumn{2}{|c|}{$\begin{array}{l}\text { Test for residual } \\
\text { heterogeneity }\end{array}$} & \multirow[t]{2}{*}{$\begin{array}{c}\text { Residual } \\
\mathrm{I}^{2}(\%)\end{array}$} & \multirow[t]{2}{*}{$\mathrm{R}^{2}(\%)$} \\
\hline & & & & $\mathrm{Q}_{\mathrm{M}}(1 \mathrm{df})$ & $p$ & $\mathrm{QE}_{\mathrm{E}}(\mathrm{df})$ & $p$ & & \\
\hline \multicolumn{10}{|l|}{ Suicide } \\
\hline Birth order $2+$ vs 1 & $29.78(9)$ & 0.001 & 69.8 & 3.03 & 0.082 & $15.36(8)$ & 0.053 & 47.3 & 47.0 \\
\hline Birth order $2-3$ vs 1 & $17.67(6)$ & 0.007 & 66.1 & 17.67 & 0.007 & $7.87(5)$ & 0.002 & 55.8 & 36.4 \\
\hline Birth order $4+$ vs 1 & $42.45(6)$ & 0.000 & 85.9 & 1.47 & 0.226 & $19.44(5)$ & 0.002 & 26.3 & 74.2 \\
\hline Mother's age $<20$ & $20.04(6)$ & 0.027 & 70.1 & 1.43 & 0.231 & $18.88(5)$ & 0.002 & 73.5 & 0 \\
\hline Father's age $<25$ vs $25-35$ & $14.55(3)$ & 0.002 & 79.4 & 0.42 & 0.518 & $10.29(2)$ & 0.006 & 21.6 & 81.3 \\
\hline Father's age $>35$ vs $25-35$ & $6.80(3)$ & 0.079 & 55.9 & 4.85 & 0.028 & $1.95(2)$ & 0.377 & 0 & 100.0 \\
\hline Single mother & $19.31(6)$ & 0.004 & 68.9 & 7.16 & 0.007 & $6.38(5)$ & 0.271 & 27.7 & 68.9 \\
\hline Mother smoking in pregnancy & $10.75(3)$ & 0.013 & 72.1 & 3.72 & 0.054 & $2.89(2)$ & 0.235 & 30.9 & 79.4 \\
\hline Mother low education & $2.79(2)$ & 0.248 & 28.3 & 2.40 & 0.122 & $0.39(1)$ & 0.530 & 0 & 100 \\
\hline Father low education & $2.93(1)$ & 0.087 & 65.9 & . & . & . & . & . & . \\
\hline Low socioeconomic status & $10.78(5)$ & 0.056 & 53.6 & . & . & . & . & . & . \\
\hline Low birthweight & $4.12(4)$ & 0.389 & 3.0 & 1.50 & 0.221 & $2.63(3)$ & 0.452 & 0 & 100 \\
\hline Low gestational age & $4.56(4)$ & 0.336 & 11.3 & 0.18 & 0.670 & $4.34(3)$ & 0.227 & 30.9 & 0 \\
\hline Small for gestational age & $1.63(3)$ & 0.653 & 0 & 0.01 & 0.933 & $1.62(2)$ & 0.445 & 0 & . \\
\hline Caesarean section & $0.08(1)$ & 0.776 & 0 & . & . & . & . & . & . \\
\hline Hypertensive disease & $0.10(1)$ & 0.749 & 0 & . & . & . & . & . & . \\
\hline \multicolumn{10}{|l|}{ Suicide attempt } \\
\hline Birth order $2+$ vs 1 & $7.58(4)$ & 0.108 & 47.3 & 5.73 & 0.018 & $1.86(3)$ & 0.602 & 0 & 100 \\
\hline Mother's age $<20$ & $14.65(3)$ & 0.002 & 79.5 & 0.04 & 0.838 & $14.11(2)$ & 0.001 & 85.8 & 0 \\
\hline Single mother & $1.54(2)$ & 0.463 & 0 & 0.41 & 0.522 & $1.13(1)$ & 0.288 & 11.5 & 0 \\
\hline Low socioeconomic status & $3.60(4)$ & 0.463 & 0 & 0.50 & 0.478 & $3.08(3)$ & 0.38 & . & 2.5 \\
\hline Low birthweight & $0(1)$ & 0.986 & 0 & . & . & . & . & . & . \\
\hline Low gestational age & $0.67(1)$ & 0.413 & 0 & . & . & . & . & . & . \\
\hline \multicolumn{10}{|l|}{ Suicidal ideation } \\
\hline Mother's age $<20$ & $0.28(1)$ & 0.594 & 0 & . & . & . & . & . & . \\
\hline Low birthweight & $0.03(1)$ & 0.853 & 0 & . & . & . & . & . & . \\
\hline
\end{tabular}

$\mathrm{I}^{2}$ reflects the proportion of heterogeneity

$\mathrm{Q}_{\mathrm{H}}$ is the test for heterogeneity in the non-moderated model; $\mathrm{Q}_{\mathrm{M}}$ is the test for moderation; $\mathrm{QE}$ is the test of heterogeneity after taking into account the moderator in the model. $\mathrm{Q}_{\mathrm{H} \sim} \mathrm{Q}_{\mathrm{M}}+\mathrm{Q}_{\mathrm{E}}\left(\mathrm{Q}_{\mathrm{H}}=\mathrm{Q}_{\mathrm{M}}+\mathrm{Q}_{\mathrm{E}}\right.$ only in a fixed-effect model $)$

$\mathrm{R}^{2}$ is the proportion of heterogeneity explained by the moderator "age at follow-up ( $\leq 30$ years versus $>30$ years)" in the metaregression model. 
Supplementary Table 15. Risk of publication bias analysis: Egger test, Timm \& Fill, and Funnel plot

\begin{tabular}{|c|c|c|c|}
\hline & \multirow{2}{*}{ Egger test $p$} & \multicolumn{2}{|r|}{ Trim \& Fill } \\
\hline & & $\mathrm{n}$ & $p$ pooled estimate \\
\hline \multicolumn{4}{|l|}{ Suicide } \\
\hline Birth order $2+$ vs 1 & 0.293 & . & . \\
\hline Birth order 2-3 vs 1 & 0.493 & . & . \\
\hline Birth order $4+$ vs 1 & 0.201 & . & . \\
\hline Mother's age $<20$ & 0.034 & 3 & $<0.001$ \\
\hline Father's age $<25$ vs $25-35$ & 0.813 & . & . \\
\hline Father's age $>35$ vs $25-35$ & 0.443 & . & . \\
\hline Single mother & 0.895 & . & . \\
\hline Mother smoking in pregnancy & 0.002 & 2 & $<0.001$ \\
\hline Mother low education & 0.772 & . & . \\
\hline Father low education & . & . & . \\
\hline Low socioeconomic status & 0.072 & . & . \\
\hline Low birthweight & 0.915 & . & . \\
\hline Low gestational age & 0.623 & . & . \\
\hline Small for gestational age & 0.255 & . & . \\
\hline Caesarean section & . & . & . \\
\hline Hypertensive disease & . & . & . \\
\hline \multicolumn{4}{|l|}{ Suicide attempt } \\
\hline Birth order $2+$ vs 1 & 0.463 & . & . \\
\hline Mother's age $<20$ & 0.698 & . & . \\
\hline Single mother & 0.965 & . & . \\
\hline Low socioeconomic status & 0.147 & . & . \\
\hline Low birthweight & . & . & . \\
\hline Low gestational age & . & . & . \\
\hline \multicolumn{4}{|l|}{ Suicidal ideation } \\
\hline Mother's age $<20$ & . & . & . \\
\hline Low birthweight & . & . & . \\
\hline
\end{tabular}




\section{Supplementary Table 16. Sensitivity analyses using the E-value}

\begin{tabular}{lcc}
\hline & Pooled OR & E-value \\
\hline Suicide & & \\
Birth order 2+ vs 1 & $1.22(1.12-1.34)$ & 1.73 \\
Birth order 2-3 vs 1 & $1.18(1.07-1.30)$ & 1.64 \\
Birth order 4+ vs 1 & $1.51(1.21-1.88)$ & 2.39 \\
Mother's age & $1.80(1.52-2.14)$ & 3.00 \\
Father's age <25y vs 25-35y & $1.24(0.90-1.71)$ &. \\
Father's age >35y vs 25-35y & $1.05(0.88-1.25)$ &. \\
Single mother household & $1.57(1.31-1.89)$ & 2.59 \\
Low mother's education & $1.36(1.28-1.46)$ & 2.06 \\
Low father's education & $1.38(1.27-1.51)$ & 2.10 \\
Low socioeconomic status & $1.27(1.00-1.61)$ & 1.86 \\
Caesarean section & $1.13(0.92-1.40)$ &. \\
Low birthweight & $1.30(1.09-1.55)$ & 1.92 \\
Low gestational age & $1.08(0.89-1.32)$ &. \\
Small for gestational age & $1.18(1.00-1.40)$ & .64 \\
Mother's smoking during pregnancy & $1.56(0.99-2.46)$ &. \\
Mother's hypertensive disease & $1.09(0.69-1.72)$ &. \\
Suicide attempt & & \\
Birth order 2+ vs 1 & &. \\
Low mother's age & $1.17(0.97-1.41)$ &. \\
Single mother household & $1.81(1.32-2.50)$ & 3.02 \\
Low socioeconomic status & $1.78(1.29-2.45)$ & 2.96 \\
Low birthweight & $1.75(1.47-2.09)$ & 2.90 \\
Low gestational age & $1.39(1.23-1.56)$ & 2.13 \\
Suicidal ideation & $1.09(1.04-1.15)$ & \\
Low mother's age & & \\
Low birthweight & $1.28(0.84-1.94)$ & .40 \\
\hline
\end{tabular}


Supplementary table 17. Crude and adjusted associations between in-utero and perinatal influences and suicide among studies controlling for parental psychopathology (in bold)

\begin{tabular}{|c|c|c|c|c|c|}
\hline $\begin{array}{l}\text { In-utero/perinatal } \\
\text { factors }\end{array}$ & $\begin{array}{l}\text { Categorisat } \\
\text { ion }^{\text {a }}\end{array}$ & $\begin{array}{l}\text { Crude } \\
\text { association }^{\text {b,c }}\end{array}$ & $\begin{array}{l}\text { Adjusted } \\
\text { association }\end{array}$ & $\begin{array}{l}\text { Method of } \\
\text { adjustment for } \\
\text { parental } \\
\text { psychopathology }\end{array}$ & Adjustment variables \\
\hline \multicolumn{6}{|l|}{ Birth order } \\
\hline $\begin{array}{l}\text { Alaräisänen } \\
2012^{d}\end{array}$ & $\begin{array}{l}1 \\
2-5 \\
6+\end{array}$ & $\begin{array}{l}1.35(0.74-2.46) \\
\text { Ref } \\
2.39(1.20-4.78)\end{array}$ & $\begin{array}{l}1.00(0.51-1.96) \\
\text { Ref } \\
2.74(1.19-6.29)\end{array}$ & Multiple regression & $\begin{array}{l}\text { Mother's antenatal depressed mood, mother's } \\
\text { psychiatric disorder, mother's age at birth }\end{array}$ \\
\hline Bjørngaard 2013 & $\begin{array}{l}1 \\
2 \\
3 \\
4+\end{array}$ & $\begin{array}{l}\text { Ref } \\
1.22(1.12-1.33) \\
1.28(1.15-1.42) \\
1.42(1.26-1.60)\end{array}$ & $\begin{array}{l}\text { Ref } \\
1.60(1.37-1.86) \\
2.12(1.62-2.76) \\
3.05(2.04-4.58)\end{array}$ & Sibling design & $\begin{array}{l}\text { Sex, age (time variable), birth period, maternal } \\
\text { age, and birth order }\end{array}$ \\
\hline $\begin{array}{l}\text { Niederkrotenthal } \\
\text { er } 2012\end{array}$ & $\begin{array}{l}1 \\
2-3 \\
4+\end{array}$ & $\begin{array}{l}0.99(0.88-1.11) \\
\text { Ref } \\
1.34(1.07-1.69)\end{array}$ & $\begin{array}{l}0.89(0.78-1.01) \\
\text { Ref } \\
1.18(0.92-1.51)\end{array}$ & Multiple regression & $\begin{array}{l}\text { Maternal age, paternal age, birth weight, } \\
\text { gestational age, parental socio-economic and } \\
\text { maternal civil status in childhood, parental } \\
\text { death due to suicide and other causes; } \\
\text { parental suicide attempt and inpatient care } \\
\text { due to mental disorders }\end{array}$ \\
\hline Rostila 2014 & $\begin{array}{l}1 \\
2 \\
3 \\
4+\end{array}$ & NA & $\begin{array}{l}\text { Ref } \\
1.17(1.05-1.30) \\
1.39(1.18-1.65) \\
1.57(1.23-2.00)\end{array}$ & Sibling design & $\begin{array}{l}\text { Age, period, sex, and maternal age at child's } \\
\text { birth, marital status, socioeconomic status }\end{array}$ \\
\hline Saarela 2016 & $\begin{array}{l}1 \\
2 \\
3 \\
4+\end{array}$ & NA & $\begin{array}{l}\text { Ref } \\
1.27(1.09-1.47) \\
1.35(1.05-1.73) \\
1.72(1.22-2.44)\end{array}$ & Sibling design & $\begin{array}{l}\text { Age, birth year, sex, and parental age at child } \\
\text { birth }\end{array}$ \\
\hline \multicolumn{6}{|l|}{ Mother's age } \\
\hline $\begin{array}{l}\text { Alaräisänen } \\
2012^{\mathrm{d}}\end{array}$ & $\begin{array}{l}<20 \\
20-34 \\
35+\end{array}$ & $\begin{array}{l}2.20(1.02-4.73) \\
\text { Ref } \\
0.80(0.37-1.70)\end{array}$ & $\begin{array}{l}2.41(1.02-5.71) \\
\operatorname{Ref} \\
0.42(0.17-1.07)\end{array}$ & Multiple regression & $\begin{array}{l}\text { Mother's antenatal depressed mood, mother's } \\
\text { psychiatric disorder, birth order }\end{array}$ \\
\hline Bjørngaard 2013 & $\begin{array}{l}<20 \\
20-24 \\
25-29 \\
30-34 \\
35+\end{array}$ & $\begin{array}{l}\text { Ref } \\
0.72(0.64-0.81) \\
0.67(0.59-0.75) \\
0.69(0.60-0.79) \\
0.71(0.60-0.84)\end{array}$ & $\begin{array}{l}\text { Ref } \\
0.87(0.69-1.09) \\
0.72(0.52-0.99) \\
0.62(0.40-0.96) \\
0.53(0.30-0.94)\end{array}$ & Sibling design & $\begin{array}{l}\text { Sex, age (time variable), birth period, maternal } \\
\text { age, and birth order }\end{array}$ \\
\hline Ekeus 2006 & $\begin{array}{l}<20 \\
20-24 \\
25-29 \\
30-34 \\
35+\end{array}$ & $\begin{array}{l}2.4(1.7-3.3) \\
1.5(1.1-1.9) \\
\text { Ref } \\
1.7(1.1-2.6) \\
2.0(1.0-3.8)\end{array}$ & $\begin{array}{l}1.5(1.0-2.3) \\
1.3(0.9-1.7) \\
\text { Ref } \\
1.5(1.0-2.3) \\
1.4(0.7-2.8)\end{array}$ & Multiple regression & $\begin{array}{l}\text { Age, sex, child welfare intervention, illicit drug } \\
\text { abuse in parents, alcohol addiction in parents, } \\
\text { psychiatric illness in parents, housing, } \\
\text { residency, social welfare, ethnicity, SES, single } \\
\text { parenthood and paternal age }\end{array}$ \\
\hline Mok 2017 & $\begin{array}{l}<20 \\
20-24 \\
25-29 \\
30-34 \\
35-39 \\
40+\end{array}$ & $\begin{array}{l}1.46(1.19-1.79) \\
1.30(1.16-1.47) \\
\text { Ref } \\
1.01(0.87-1.16) \\
1.15(0.92-1.42) \\
0.77(0.45-1.23)\end{array}$ & $\begin{array}{l}1.24(1.00-1.52) \\
1.22(1.08-1.38) \\
\text { Ref } \\
1.02(0.88-1.18) \\
1.15(0.91-1.43) \\
0.84(0.47-1.40)\end{array}$ & Multiple regression & $\begin{array}{l}\text { Father's age, offspring age and sex, and calendar } \\
\text { year, parental histories of mental illnesses, } \\
\text { parental socioeconomic status, and urbanicity of } \\
\text { birthplace }\end{array}$ \\
\hline $\begin{array}{l}\text { Niederkrotenthal } \\
\text { er } 2012\end{array}$ & $\begin{array}{l}<20 \\
20-29 \\
30+\end{array}$ & $\begin{array}{l}1.82(1.41-2.36) \\
\operatorname{Ref} \\
0.99(0.87-1.13)\end{array}$ & $\begin{array}{l}1.90(1.44-2.49) \\
\operatorname{Ref} \\
0.95(0.81-1.11)\end{array}$ & Multiple regression & $\begin{array}{l}\text { Birth weight, gestational age and parity, parental } \\
\text { socio-economic and maternal civil status in } \\
\text { childhood, parental death due to suicide and } \\
\text { other causes; parental suicide attempt and } \\
\text { inpatient care due to mental disorders }\end{array}$ \\
\hline $\begin{array}{l}\text { Von } \\
\text { Borczyskowski } \\
2010\end{array}$ & $\begin{array}{l}<25 \\
25-34 \\
35+ \\
\end{array}$ & $\begin{array}{l}1.16(1.11-1.21) \\
\text { Ref } \\
1.11(1.05-1.17)\end{array}$ & $\begin{array}{l}1.13(1.07-1.19) \\
\text { Ref } \\
1.14(1.07-1.21)\end{array}$ & Multiple regression & $\begin{array}{l}\text { Age and parents' morbidity, ie, suicide of } \\
\text { parent(s), severe psychiatric disorders of the } \\
\text { parent(s), alcohol abuse of the parent(s) }\end{array}$ \\
\hline \multicolumn{6}{|l|}{ Single mother } \\
\hline $\begin{array}{l}\text { Von } \\
\text { Borczyskowski } \\
2010\end{array}$ & $\begin{array}{l}\text { Single } \\
\text { Two parents }\end{array}$ & $\begin{array}{l}1.46(1.39-1.54) \\
\text { Ref }\end{array}$ & $\begin{array}{l}1.33(1.25-1.42) \\
\text { Ref }\end{array}$ & Multiple regression & $\begin{array}{l}\text { Age and parents' morbidity, ie, suicide of } \\
\text { parent(s), severe psychiatric disorders of the } \\
\text { parent(s), alcohol abuse of the parent(s) }\end{array}$ \\
\hline \multicolumn{6}{|l|}{$\begin{array}{l}\text { Socioeconomic } \\
\text { status }\end{array}$} \\
\hline $\begin{array}{l}\text { Von } \\
\text { Borczyskowski } \\
2010\end{array}$ & $\begin{array}{l}\text { White collar } \\
\text { Blue collar } \\
\text { NA/other }\end{array}$ & $\begin{array}{l}\text { Ref } \\
1.15(1.10-1.21) \\
1.14(1.08-1.21)\end{array}$ & $\begin{array}{l}\text { Ref } \\
1.13(1.08-1.19) \\
1.12(1.06-1.19)\end{array}$ & Multiple regression & $\begin{array}{l}\text { Age and parents' morbidity, ie, suicide of } \\
\text { parent(s), severe psychiatric disorders of the } \\
\text { parent(s), alcohol abuse of the parent(s) }\end{array}$ \\
\hline \multicolumn{6}{|l|}{ Birthweight } \\
\hline $\begin{array}{l}\text { Niederkrotenthal } \\
\text { er } 2012\end{array}$ & $\begin{array}{l}800-2499 \\
2500-3250 \\
3250-3750 \\
3750-4450 \\
4450-6000\end{array}$ & $\begin{array}{l}1.82(1.37-2.43) \\
1.11(0.96-1.28) \\
\text { Ref } \\
1.07(0.93-1.23) \\
0.77(0.54-1.11)\end{array}$ & $\begin{array}{l}1.65(1.16-2.35) \\
1.04(0.89-1.21) \\
\text { Ref } \\
1.07(0.93-1.24) \\
0.77(0.53-1.12)\end{array}$ & Multiple regression & $\begin{array}{l}\text { Gestational age, parity, maternal and paternal } \\
\text { age, parental socio-economic and maternal civil } \\
\text { status in childhood, parental death due to } \\
\text { suicide and other causes; parental suicide } \\
\text { attempt and inpatient care due to mental } \\
\text { disorders }\end{array}$ \\
\hline
\end{tabular}




\begin{tabular}{|c|c|c|c|c|c|}
\hline $\begin{array}{l}\text { Niederkrotenthal } \\
\text { er } 2012\end{array}$ & $\begin{array}{l}<48 \\
48-49 \\
50-51 \\
52-53 \\
54+\end{array}$ & $\begin{array}{l}1.40(1.14-1.71) \\
1.04(0.89-1.22) \\
\text { Ref } \\
1.03(0.89-1.19) \\
0.80(0.64-1.00)\end{array}$ & $\begin{array}{l}1.20(0.95-1.52) \\
0.98(0.83-1.16) \\
\text { Ref } \\
1.03(0.89-1.19) \\
0.81(0.65-1.02)\end{array}$ & Multiple regression & $\begin{array}{l}\text { Gestational age, parity, maternal and paternal } \\
\text { age, parental socio-economic and maternal civil } \\
\text { status in childhood, parental death due to } \\
\text { suicide and other causes; parental suicide } \\
\text { attempt and inpatient care due to mental } \\
\text { disorders }\end{array}$ \\
\hline \multicolumn{6}{|r|}{ (1) } \\
\hline $\begin{array}{l}\text { Niederkrotenthal } \\
\text { er } 2012\end{array}$ & $\begin{array}{l}\text { Low weight } \\
\text { and length } \\
\text { Low weight } \\
\text { Short length } \\
\text { Non-SGA }\end{array}$ & $\begin{array}{l}1.38(0.94-2.03) \\
1.39(0.85-2.28) \\
1.14(0.82-1.59) \\
\text { Ref }\end{array}$ & $\begin{array}{l}1.18(0.79-1.76) \\
1.25(0.75-2.08) \\
0.97(0.69-1.36) \\
\text { Ref }\end{array}$ & Multiple regression & $\begin{array}{l}\text { Parity, maternal and paternal age, parental } \\
\text { socio-economic and maternal civil status in } \\
\text { childhood, parental death due to suicide and } \\
\text { other causes; parental suicide attempt and } \\
\text { inpatient care due to mental disorders }\end{array}$ \\
\hline
\end{tabular}

NA, not available; SGA, Small for gestational age; ${ }^{a}$ see supplemental material tables S3 to S14 for details about exposure categorisation; ${ }^{b}$ minimally adjusted model is reported if the crude association is not available; for sibling design, the association in the entire population is reported, if available; ${ }^{\mathrm{c}}$ estimates can be odds ratio, risk ratio, hazard ratio, incidence rate ratio; see papers for details. ${ }^{\mathrm{d}}$ reported only for males 
Supplementary table 18. Crude and adjusted association between in-utero and perinatal influences and suicide attempt among studies controlling for parental psychopathology (in bold)

\begin{tabular}{|c|c|c|c|c|c|}
\hline Early-life factor & $\begin{array}{l}\text { Categorisat } \\
\text { ion }^{\text {a }}\end{array}$ & $\begin{array}{l}\text { Crude } \\
\text { association }^{\text {b,c }}\end{array}$ & $\begin{array}{l}\text { Adjusted } \\
\text { association }\end{array}$ & $\begin{array}{l}\text { Method of } \\
\text { adjustment for } \\
\text { parental } \\
\text { psychopathology }\end{array}$ & Adjustment variables \\
\hline \multicolumn{6}{|l|}{ Birth order } \\
\hline $\begin{array}{l}\text { Niederkrotenthal } \\
\text { er } 2012\end{array}$ & $\begin{array}{l}1 \\
2-3 \\
4+\end{array}$ & $\begin{array}{l}0.97(0.93-1.00) \\
\text { Ref } \\
1.56(1.46-1.66)\end{array}$ & $\begin{array}{l}0.80(0.77-0.84) \\
\text { Ref } \\
1.40(1.31-1.50)\end{array}$ & Multiple regression & $\begin{array}{l}\text { Maternal age, paternal age, birth weight, } \\
\text { gestational age, parental socio-economic and } \\
\text { maternal civil status in childhood, parental } \\
\text { death due to suicide and other causes; } \\
\text { parental suicide attempt and inpatient care } \\
\text { due to mental disorders }\end{array}$ \\
\hline \multicolumn{6}{|l|}{ Mother's age } \\
\hline $\begin{array}{l}\text { Niederkrotenthal } \\
\text { er } 2012\end{array}$ & $\begin{array}{l}<20 \\
20-29 \\
30+\end{array}$ & $\begin{array}{l}2.11(1.96-2.27) \\
\text { Ref } \\
0.86(0.83-0.89)\end{array}$ & $\begin{array}{l}1.66(1.53-1.80) \\
\text { Ref } \\
0.83(0.79-0.86)\end{array}$ & Multiple regression & $\begin{array}{l}\text { Birth weight, gestational age and parity, parental } \\
\text { socio-economic and maternal civil status in } \\
\text { childhood, parental death due to suicide and } \\
\text { other causes; parental suicide attempt and } \\
\text { inpatient care due to mental disorders }\end{array}$ \\
\hline Ekeus 2006 & $\begin{array}{l}<20 \\
20-24 \\
25-29 \\
30-34 \\
35+\end{array}$ & $\begin{array}{l}2.0(1.7-2.3) \\
1.3(1.1-1.5) \\
\operatorname{Ref} \\
1.0(0.8-1.2) \\
1.3(0.9-1.8)\end{array}$ & $\begin{array}{l}1.6(1.4-1.9) \\
1.2(1.1-1.4) \\
\text { Ref } \\
0.9(0.8-1.2) \\
1.2(0.8-1.7)\end{array}$ & Multiple regression & $\begin{array}{l}\text { Age, sex, child welfare intervention, illicit drug } \\
\text { abuse in parents, alcohol addiction in parents, } \\
\text { psychiatric illness in parents, housing, } \\
\text { residency, social welfare, ethnicity, SES, single } \\
\text { parenthood and paternal age }\end{array}$ \\
\hline Mok 2017 & $\begin{array}{l}<20 \\
20-24 \\
25-29 \\
30-34 \\
35-39 \\
40+ \\
\end{array}$ & $\begin{array}{l}1.93(1.85-2.02) \\
1.33(1.30-1.37) \\
\text { Ref } \\
0.92(0.89-0.95) \\
0.94(0.89-0.99) \\
1.03(0.93-1.14) \\
\end{array}$ & $\begin{array}{l}1.43(1.37-1.49) \\
1.17(1.14-1.20) \\
\text { Ref } \\
0.96(0.93-0.99) \\
0.96(0.91-1.01) \\
1.02(0.91-1.14)\end{array}$ & Multiple regression & $\begin{array}{l}\text { Father's age, offspring age and sex, and calendar } \\
\text { year, parental histories of mental illnesses, } \\
\text { parental socioeconomic status, and urbanicity of } \\
\text { birthplace }\end{array}$ \\
\hline \multicolumn{6}{|l|}{ Single parent } \\
\hline $\begin{array}{l}\text { Alaräisänen } \\
2012^{d}\end{array}$ & $\begin{array}{l}\text { No } \\
\text { Yes }\end{array}$ & $\begin{array}{l}\text { Ref } \\
5.46(2.64-11.29)\end{array}$ & $\begin{array}{l}\text { Ref } \\
4.02(1.80-08.95)\end{array}$ & Multiple regression & $\begin{array}{l}\text { Unwanted pregnancy, mothers smoked during } \\
\text { pregnancy, single parent family, father's } \\
\text { psychiatric disorder }\end{array}$ \\
\hline \multicolumn{6}{|l|}{$\begin{array}{l}\text { Socioeconomic } \\
\text { status }\end{array}$} \\
\hline Page 2014 & $\begin{array}{l}\text { I/II } \\
\text { III/IV } \\
\text { V/VI }\end{array}$ & $\begin{array}{l}\text { Ref } \\
0.99(0.81-1.19) \\
1.10(0.69-1.77)\end{array}$ & $\begin{array}{l}\text { Ref } \\
1.00(0.80-1.25) \\
1.16(0.69-1.95)\end{array}$ & Multiple regression & $\begin{array}{l}\text { Sex, age, substance use, maternal depression, } \\
\text { other socioeconomic position measures, and } \\
\text { depressive symptoms at } 10.5,13 \text { and } 16 \text { years }\end{array}$ \\
\hline \multicolumn{6}{|l|}{$\begin{array}{l}\text { Maternal } \\
\text { education }\end{array}$} \\
\hline Page 2014 & $\begin{array}{l}\text { A } \\
\text { level/degree } \\
\text { O level } \\
\text { CSE/ } \\
\text { vocational }\end{array}$ & $\begin{array}{l}\text { Ref } \\
1.16(0.95-1.40) \\
0.84(0.66-1.08)\end{array}$ & $\begin{array}{l}\text { Ref } \\
1.09(0.88-1.36) \\
0.72(0.53-0.96)\end{array}$ & Multiple regression & $\begin{array}{l}\text { Sex, age, substance use, maternal depression, } \\
\text { other socioeconomic position measures, and } \\
\text { depressive symptoms at } 10.5,13 \text { and } 16 \text { years }\end{array}$ \\
\hline \multicolumn{6}{|l|}{ Birthweight } \\
\hline Class 2014 & $\begin{array}{l}\leq 2500 \\
2500+\end{array}$ & $\begin{array}{l}1.19(1.11-1.28) \\
\text { Ref }\end{array}$ & $\begin{array}{l}0.94(0.81-1.10) \\
\text { Ref }\end{array}$ & Sibling design & Gender, birth order, gestational age, year of birth \\
\hline $\begin{array}{l}\text { Niederkrotenthal } \\
\text { er } 2012\end{array}$ & $\begin{array}{l}800-2499 \\
2500-3250 \\
3250-3750 \\
3750-4450 \\
4450-6000\end{array}$ & $\begin{array}{l}1.30(1.19-1.42) \\
1.13(1.08-1.17) \\
\text { Ref } \\
0.93(0.89-0.97) \\
0.93(0.84-1.04)\end{array}$ & $\begin{array}{l}1.12(1.01-1.25) \\
1.06(1.02-1.11) \\
\text { Ref } \\
0.95(0.91-0.99) \\
0.97(0.87-1.09)\end{array}$ & Multiple regression & $\begin{array}{l}\text { Gestational age, parity, maternal and paternal } \\
\text { age, parental socio-economic and maternal civil } \\
\text { status in childhood, parental death due to } \\
\text { suicide and other causes; parental suicide } \\
\text { attempt and inpatient care due to mental } \\
\text { disorders }\end{array}$ \\
\hline \multicolumn{6}{|l|}{ Birth length } \\
\hline $\begin{array}{l}\text { Niederkrotenthal } \\
\text { er } 2012\end{array}$ & $\begin{array}{l}<48 \\
48-49 \\
50-51 \\
52-53 \\
54+\end{array}$ & $\begin{array}{l}1.29(1.22-1.36) \\
1.10(1.05-1.15) \\
\text { Ref } \\
0.90(0.86-0.94) \\
0.87(0.81-0.94)\end{array}$ & $\begin{array}{l}1.15(1.08,1.22) \\
1.05(1.00,1.10) \\
\text { Ref } \\
0.92(0.88,0.97) \\
0.91(0.84,0.98)\end{array}$ & Multiple regression & $\begin{array}{l}\text { Gestational age, parity, maternal and paternal } \\
\text { age, parental socio-economic and maternal civil } \\
\text { status in childhood, parental death due to } \\
\text { suicide and other causes; parental suicide } \\
\text { attempt and inpatient care due to mental } \\
\text { disorders }\end{array}$ \\
\hline \multicolumn{6}{|l|}{ SGA } \\
\hline $\begin{array}{l}\text { Niederkrotenthal } \\
\text { er } 2012\end{array}$ & $\begin{array}{l}\text { Low weight } \\
\text { and length } \\
\text { Low weight } \\
\text { Short length } \\
\text { Non-SGA }\end{array}$ & $\begin{array}{l}1.42(1.27-1.58) \\
0.95(0.81-1.12) \\
1.30(1.20-1.42) \\
\operatorname{Ref}\end{array}$ & $\begin{array}{l}1.23(1.10-1.38) \\
0.91(0.79-1.08) \\
1.18(1.09-1.29) \\
\operatorname{Ref}\end{array}$ & Multiple regression & $\begin{array}{l}\text { Parity, maternal and paternal age, parental } \\
\text { socio-economic and maternal civil status in } \\
\text { childhood, parental death due to suicide and } \\
\text { other causes; parental suicide attempt and } \\
\text { inpatient care due to mental disorders }\end{array}$ \\
\hline
\end{tabular}

NA, not available; SGA, Small for gestational age; ${ }^{a}$ see supplemental material tables S3 to S14 for details about exposure categorisation; ${ }^{b}$ minimally adjusted model is reported if the crude association is not available; for sibling design, the association in the entire population is reported, if available; ${ }^{\mathrm{c}}$ estimates can be odds ratio, risk ratio, hazard ratio, incidence rate ratio; see papers for details. ${ }^{\mathrm{d}}$ reported only for males 
Birth order

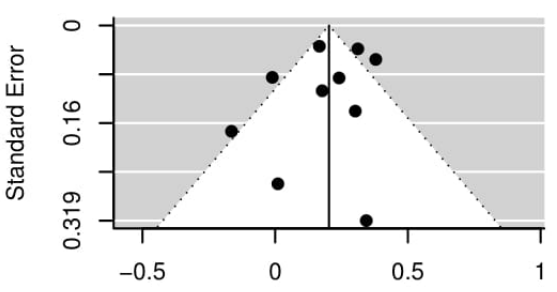

Log Odds Ratio

Father's age - advanced

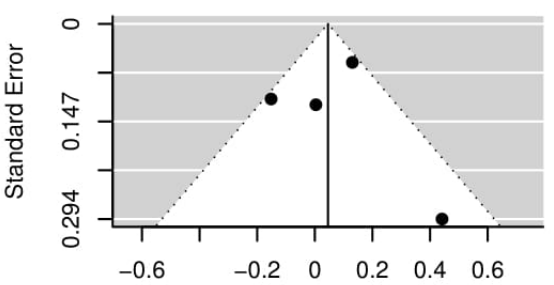

Log Odds Ratio

Father's education

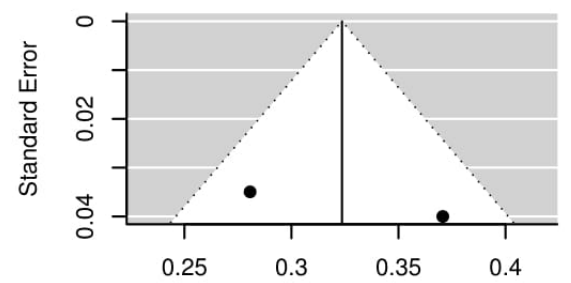

Log Odds Ratio

Birthweight

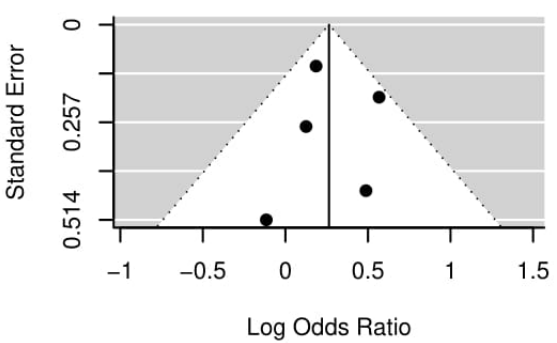

Funnel plot Smoking in pregnancy

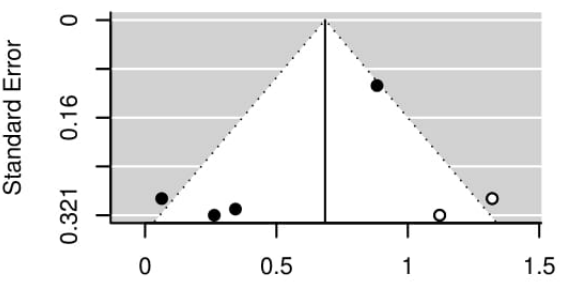

Log Odds Ratio
Mother's age

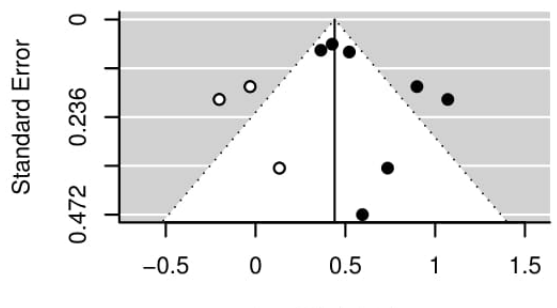

Log Odds Ratio

Single mother

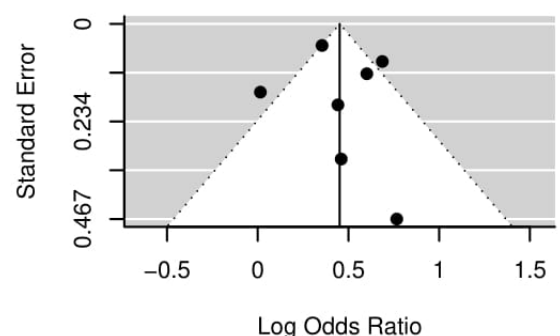

Socioeconomic Status

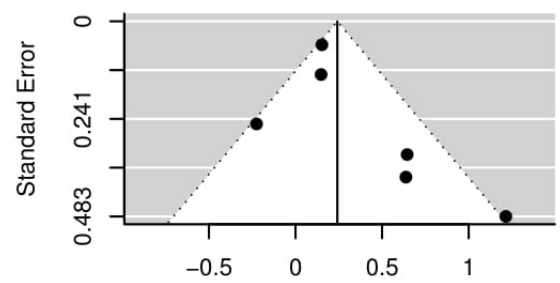

Log Odds Ratio

Gestational age

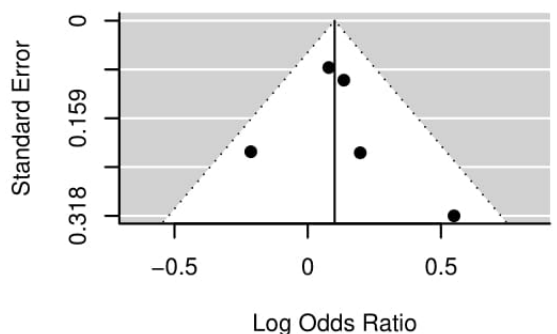

Mother's hypertension

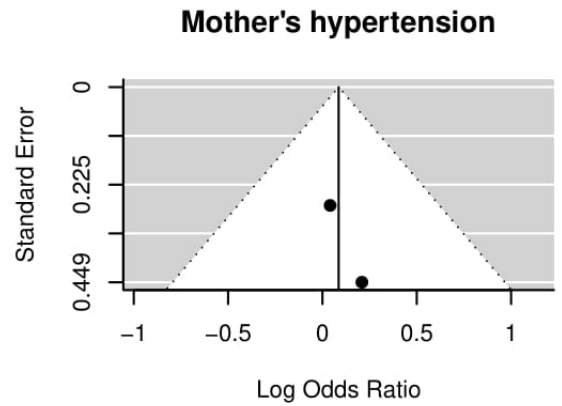

Log Odds Ratio
Father's age - young

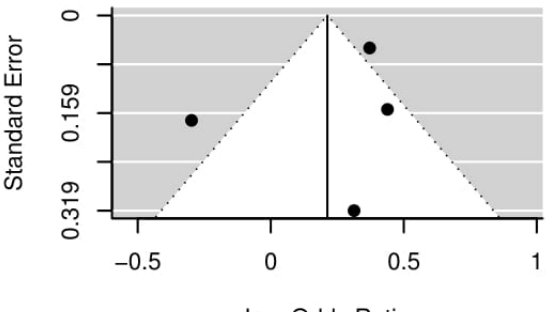

Log Odds Ratio

Mother's education

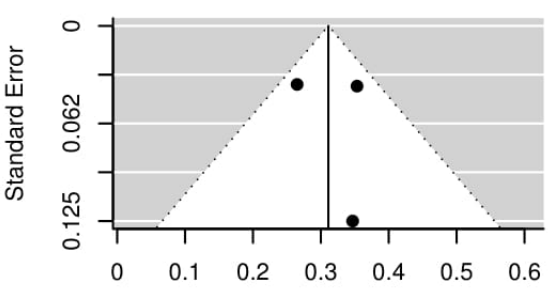

Log Odds Ratio

\section{Caesarean section}

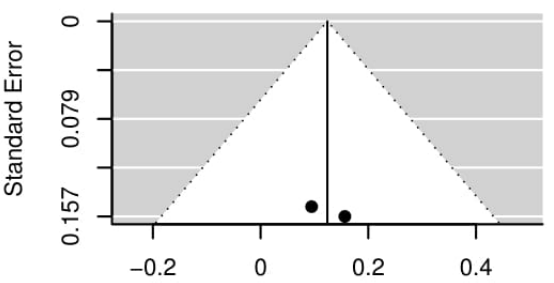

Log Odds Ratio

Small for Gestational Age

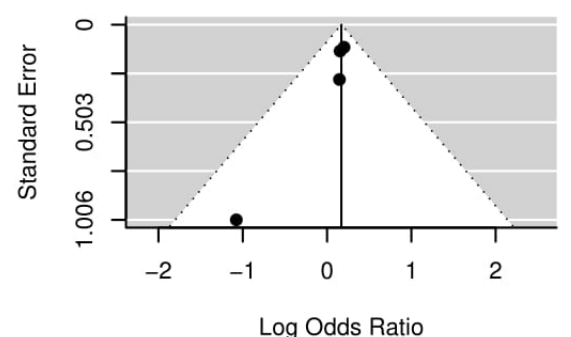

Log Odds Ratio 


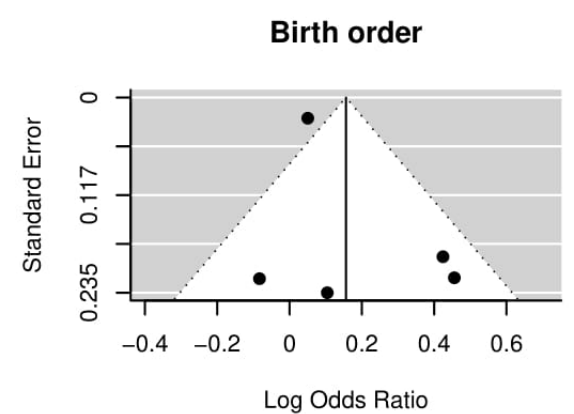

Socioeconomic status

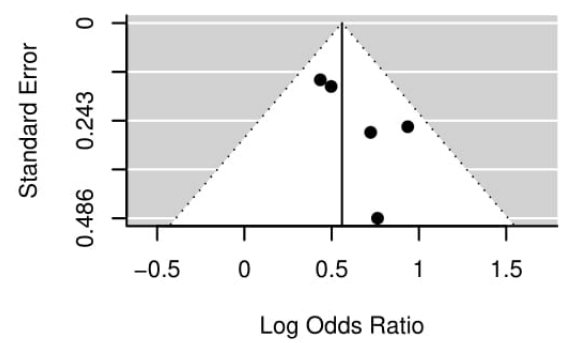

Mother's age

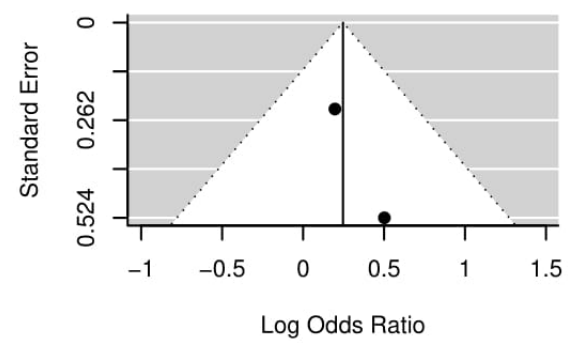

Mother's age

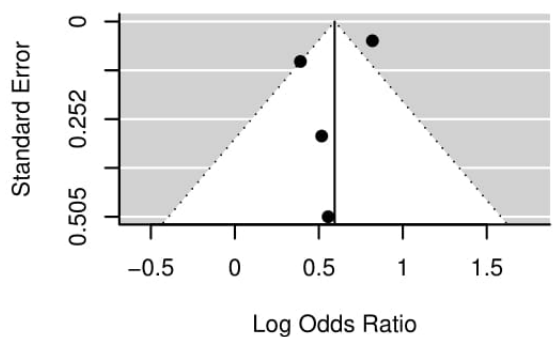

Birthweight

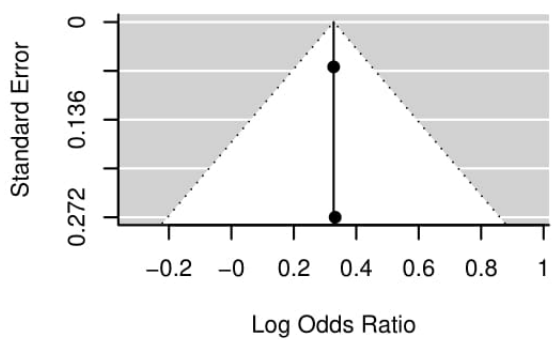

Birthweight

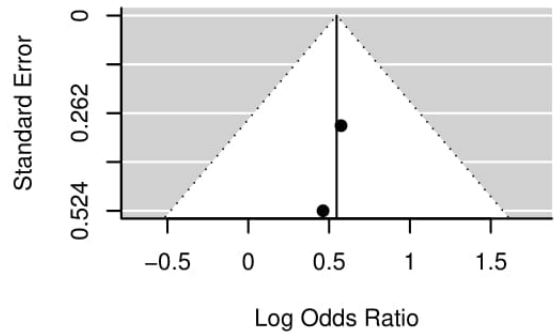

Single mother

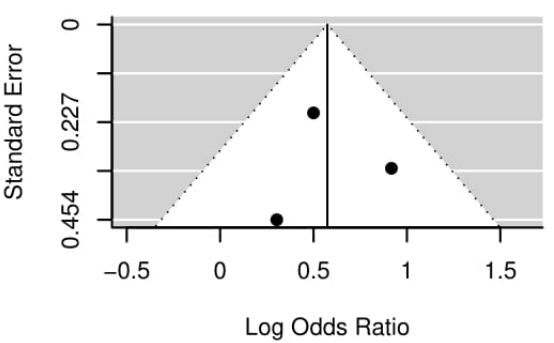

Birthweight

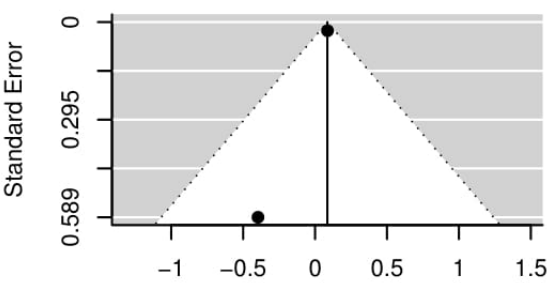

Log Odds Ratio 
Supplementary Figure 3. Sensitivity analysis using the removing-one-study method for suicide
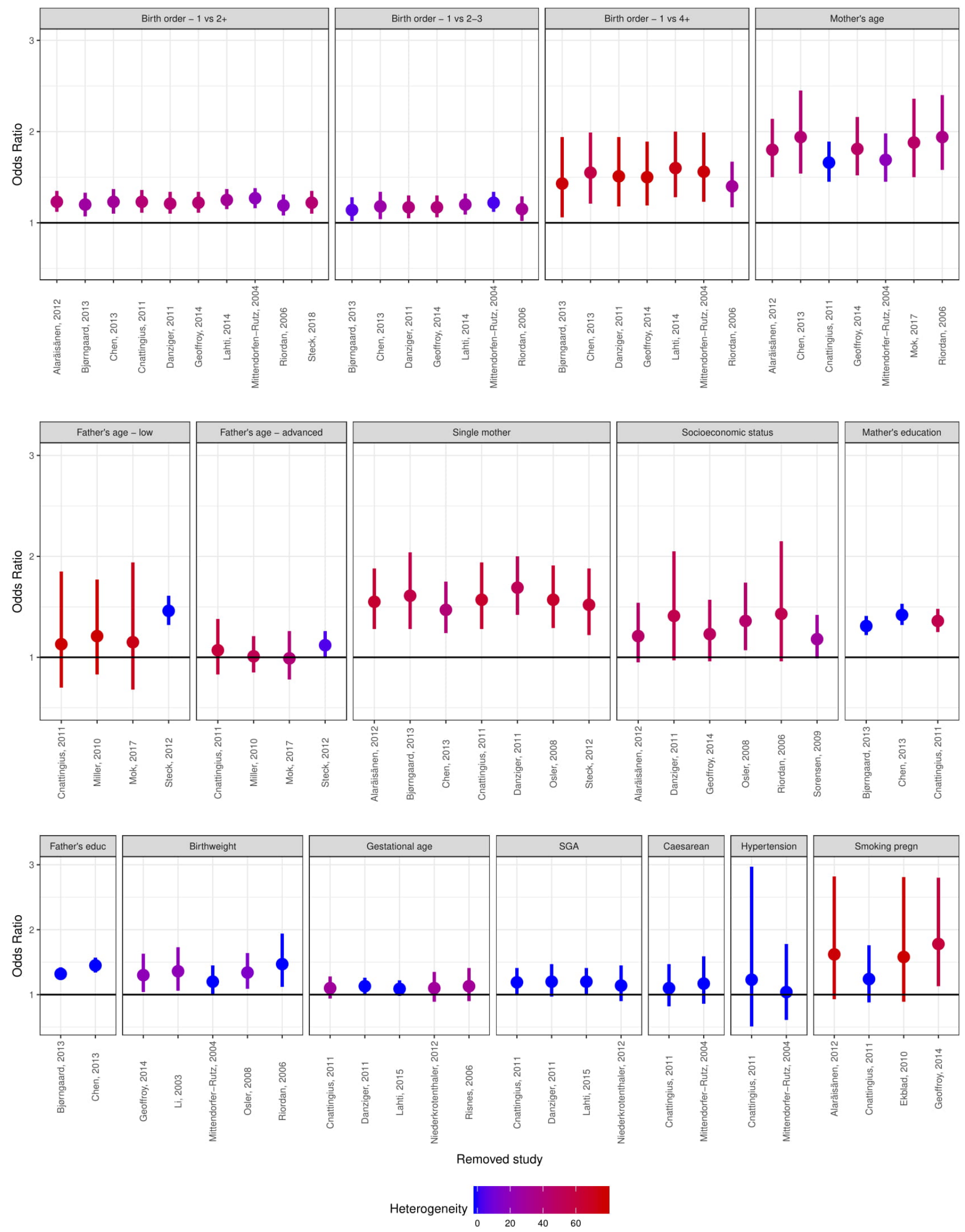
Supplementary Figure 4. Sensitivity analysis using the removing-one-study method for suicide attempt

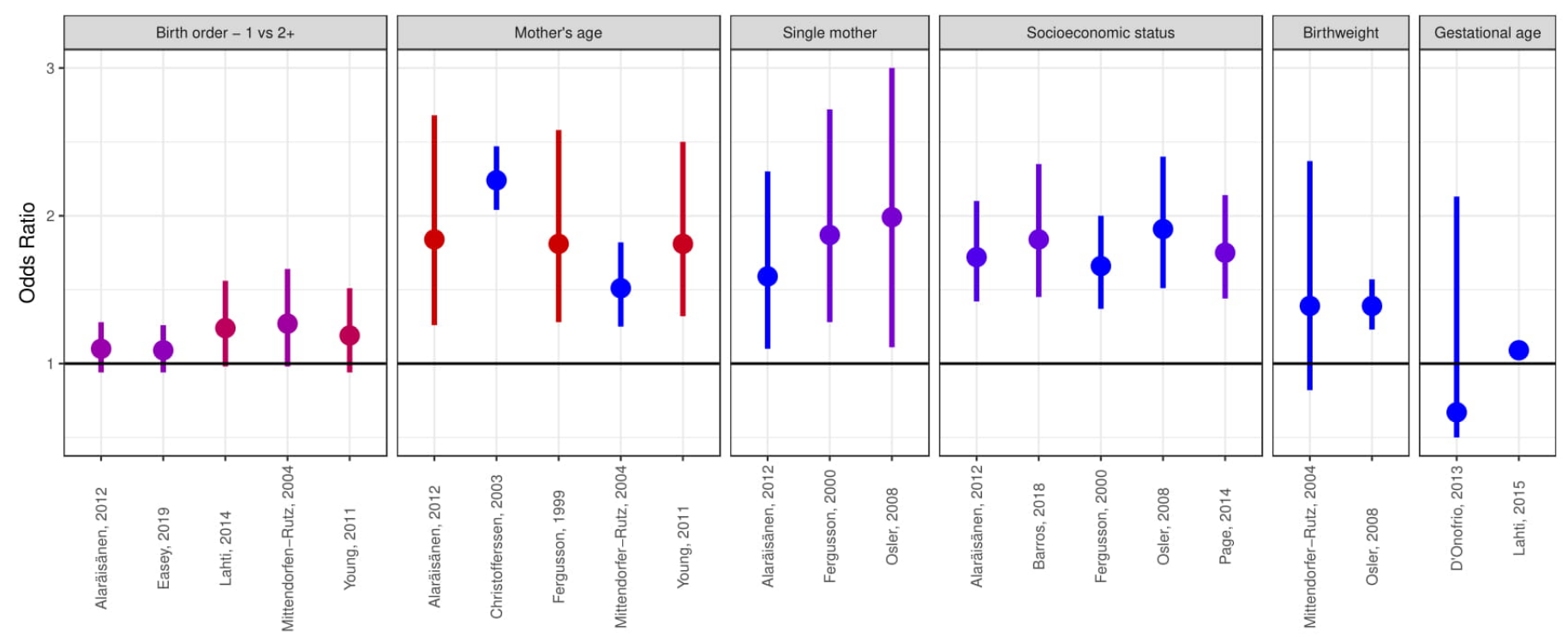




\section{Supplementary references}

1 Scottish Intercollegiate Guideline Network. Search filters. https://www.sign.ac.uk/search-filters.html (accessed Oct 1, 2018).

2 McGowan J, Sampson M, Salzwedel DM, Cogo E, Foerster V, Lefebvre C. PRESS Peer Review of Electronic Search Strategies: 2015 Guideline Statement. J Clin Epidemiol 2016; 75: 40-6.

3 Ouzzani M, Hammady H, Fedorowicz Z, Elmagarmid A. Rayyan — a web and mobile app for systematic reviews. Syst Rev 2016; 5. DOI:10.1186/s13643-016-0384-4.

4 DerSimonian R, Laird N. Meta-analysis in clinical trials. Control Clin Trials 1986; 7: 177-88.

5 VanderWeele TJ, Ding P. Sensitivity Analysis in Observational Research: Introducing the E-Value. Ann Intern Med 2017; 167: 268.

6 Cole SR, Platt RW, Schisterman EF, et al. Illustrating bias due to conditioning on a collider. Int J Epidemiol 2010; 39: 417-20.

7 Class QA, Rickert ME, Larsson H, Lichtenstein P, D’Onofrio BM. Fetal growth and psychiatric and socioeconomic problems: population-based sibling comparison. Br J Psychiatry J Ment Sci 2014; 205: 355-61. 